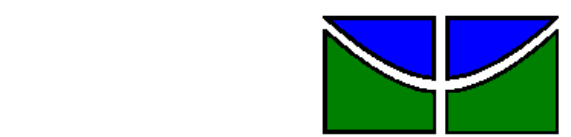

Universidade de Brasília

Faculdade de Economia, Administração e Contabilidade

Departamento de Administração

AMANDA MONTANARO LOMBARDI

\title{
INFLUÊNCIA DO BENEFÍCIO UTILITÁRIO, BENEFÍCIO INFORMATIVO E PRECOO NA QUANTIDADE DE CLIENTES, RECEITA E LUCRO PROVENIENTES DA VENDA DE COMBUSTIIVEIS AUTOMOTIVOS
}

Brasília - DF 
AMANDA MONTANARO LOMBARDI

\section{INFLUÊNCIA DO BENEFÍCIO UTILITÁRIO, BENEFÍCIO INFORMATIVO E PREÇO NA QUANTIDADE DE CLIENTES, LUCRO E RECEITA PROVENIENTES DA VENDA DE COMBUSTÍVEIS AUTOMOTIVOS}

Monografia apresentada ao

Departamento de Administração como requisito parcial à obtenção do título de Bacharel em Administração.

Professor Orientador: Doutor Rafael Barreiros Porto

Brasília - DF 
Lombardi, Amanda Montanaro.

Influência do benefício utilitário, benefício informativo e preço na quantidade de clientes, lucro e receita provenientes da venda de combustíveis automotivos / Amanda Montanaro Lombardi- Brasília, 2010.

$55 \mathrm{f}$ : : il.

Monografia (bacharelado) - Universidade de Brasília, Departamento de Administração, 2010.

Orientador: Prof. Doutor. Rafael Barreiros Porto, Departamento de Administração.

1. Estratégias de Marketing. 2. Revendedores de combustível. 3. Indicadores de desempenho. I. Título. 



\title{
INFLUÊNCIA DO BENEFÍCIO UTILITÁRIO, BENEFÍCIO INFORMATIVO E PREÇO NA QUANTIDADE DE CLIENTES, RECEITA E LUCRO PROVENIENTES DA VENDA DE COMBUSTÍVEIS AUTOMOTIVOS
}

\author{
A Comissão Examinadora, abaixo identificada, aprova o Trabalho de \\ Conclusão do Curso de Administração da Universidade de Brasília \\ do (a) aluno (a)
}

\section{Amanda Montanaro Lombardi}

\author{
Doutor, Rafael Barreiros Porto \\ Professor-Orientador \\ Mestre, Pedro Henrique Melo \\ Albuquerque \\ Professor-Examinador \\ Bacharel, Késia Rozzett Oliveira \\ Professor-Examinador
}


Dedico esse trabalho aos familiares, amigos e professores que estiveram comigo, durante a graduação. 
AGRADECIMENTOS

Agradeço a DEUS e a todos que me acompanharam nessa caminhada. 
"Você precisa fazer aquilo que pensa que não é capaz de fazer".

Eleanor Roosevelt 


\section{RESUMO}

O mercado de revendedores de combustíveis é bastante competitivo, portanto, é interessante que os gestores estejam sempre atentos para conhecerem quais estratégias de Marketing são mais efetivas para melhorar a peformance de seus estabelecimentos. O objetivo do estudo é investigar a influência do benefício utilitário, benefício informativo e preço sobre a quantidade de clientes, receita e lucro oriundo da venda de combustíveis automotivos. $O$ presente estudo aponta a relação do benefício informativo, benefício utilitário e preço no aumento ou decréscimo da quantidade de cliente, receita e lucro de revendedores de combustível, em relação ao mercado e ao próprio estabelecimento em situações de alta ou baixa concorrência e com o preço acima ou abaixo da média de mercado. O trabalho foi baseado no Modelo de Perspectiva Comportamental de Foxall (1966). A pesquisa efetuada no trabalho foi quase-experimental, na qual se utilizou dados diários de uma amostra de 16 revendedores de combustíveis automotivos. Os resultados apontam que os preditores supracitados são mais efetivos para explicar a performance no mercado e não no próprio estabelecimento.

Palavras-chave: Revendedores de combustíveis. Estratégias de Marketing. Indicadores de desempenho. 


\section{LISTA DE ILUSTRAÇÕES}

Figura 1 - Modelo de perspectiva comportamental de Foxall (1966) adaptado por Foxall, Oliveira-Castro, James e Schrezenmaier (2006), tradução nossa (Foxall, 1998).

Figura 2 - Preço de combustíveis em conformidade e em não conformidade, autoria

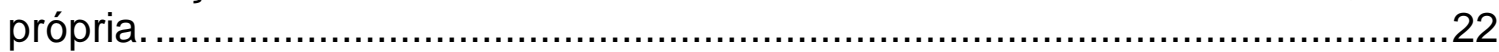

Figura 3 - modelo da metodologia, autoria própria ...........................................23

Figura 4 - Teste do poder da análise 


\section{LISTA DE TABELAS}

Tabela 1 - Divisão da amostra quanto aos serviços oferecidos ...........................27

Tabela 2 - Divisão da amostra quanto ao benefício informativo ..............................28

Tabela 3 - Divisão da amostra quanto a preço e concorrência, autoria própria. .......29

Tabela 4 - Análise da variável dependente quantidade de clientes em relação ao

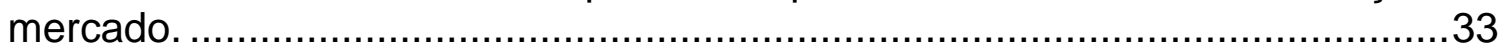

Tabela 5 - Análise da variável dependente receita em relação ao mercado. ............36

Tabela 6 - Análise da variável dependente lucro em relação ao mercado. ................39

Tabela 7 - Análise da variável dependente quantidade de clientes em relação ao

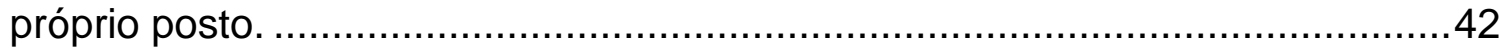

Tabela 8 - Análise da variável dependente receita em relação ao próprio revendedor.

Tabela 9 - Análise da variável dependente lucro em relação ao próprio posto.

Tabela 9 - Análise da variável dependente lucro em relação ao próprio posto. .48 


\section{SUMÁRIO}

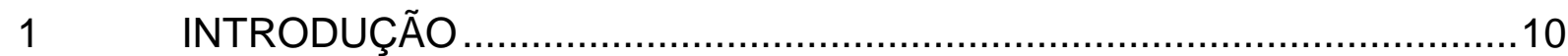

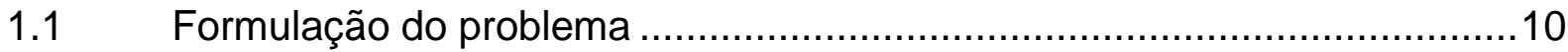

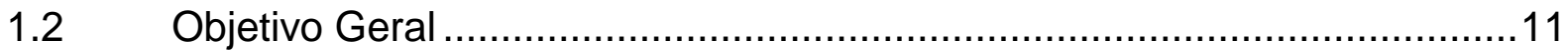

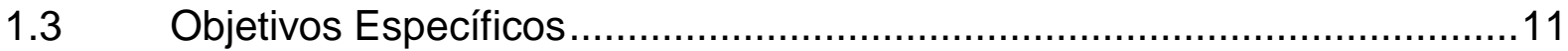

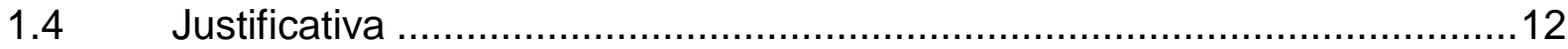

2 REFERENCIAL TEÓRICO

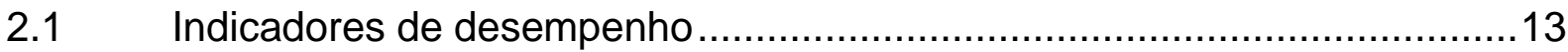

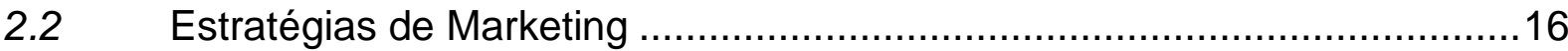

2.3 Mercado de revendedores de combustível .........................................20

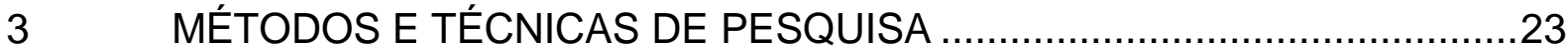

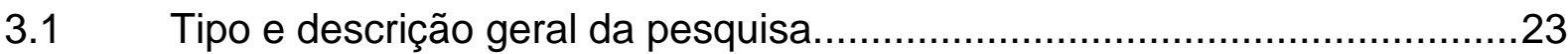

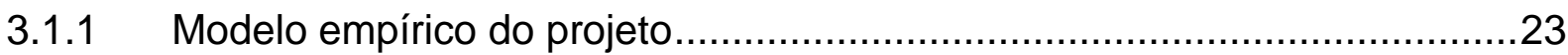

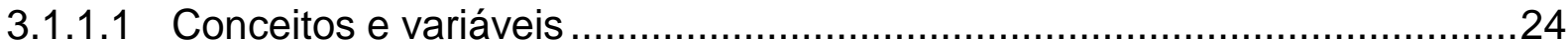

3.2 Caracterização da organização, setor ou área do objeto de estudo. ...........26

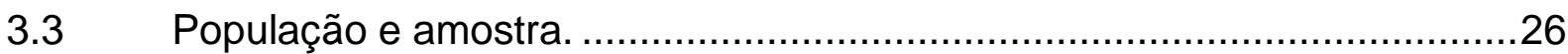

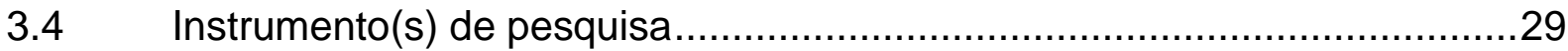

3.5 Procedimentos de coleta e de análise de dados.........................................29

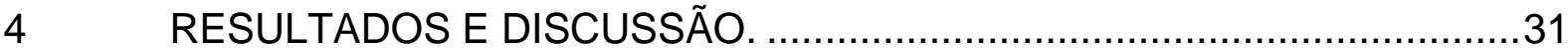

4.1 Análise da variável dependente da quantidade de clientes em relação ao mercado.

4.2 Análise da variável dependente receita proveniente da venda de combustível em relação ao mercado.

4.3 Análise da variável dependente lucro proveniente da venda de combustível em relação ao mercado.

4.4 Análise da variável dependente quantidade de clientes em relação próprio revendedor.

4.5 Análise da variável dependente receita proveniente da venda de combustível em relação próprio revendedor.

4.6 Análise da variável dependente lucro proveniente da venda de combustível em relação próprio revendedor.

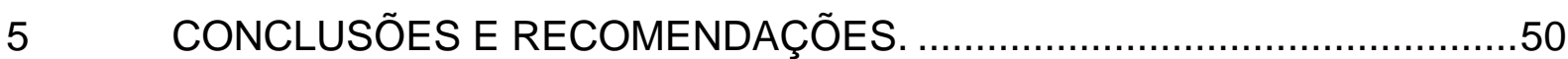

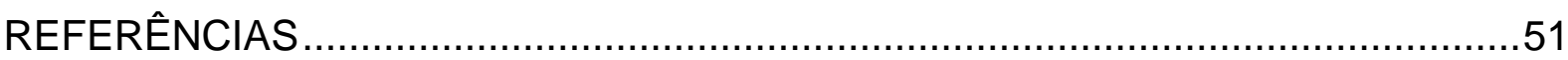




\section{INTRODUÇÃO}

O mercado de revendedores de combustíveis automotivos é bastante competitivo. Localização, preço, serviços ofertados e marca podem ser determinantes no momento do consumo. Para as empresas é fundamental identificar quais estratégias de Marketing são mais influentes para melhorar a performance da empresa, já que a cada dia que passa o consumidor tem mais alternativas na escolha de produtos e marcas para satisfazer as suas necessidades. Além disso, segundo Prusham (1999), muitos consumidores não sabem exatamente o que desejam, então o papel do profissional de Marketing é descobrir a necessidade do consumidor e oferecê-la a ele.

\subsection{Formulação do problema}

Os revendedores de combustíveis automotivos, segundo Lima (2008) apresentam um produto de alta complexidade de avaliação imediata e sua avaliação pode estar subordinada a serviços oferecidos no estabelecimento, como: lavagem automotiva, troca de óleo, loja de conveniência. Esses não são atributos do produto principal deste estabelecimento, mas apresentam a capacidade de influenciar a escolha do consumidor.

Atualmente, os postos revendedores de combustíveis automotivos não se limitam apenas à venda de combustíveis, eles tornaram-se prestadores de serviços, onde o atendente, além de abastecer o carro, oferece ao cliente outros serviços, que podem ser desfrutados pelo consumidor no próprio estabelecimento. Esses serviços, os quais são aparentemente periféricos, podem ser influenciadores na decisão de compra e estarem relacionados à demanda do produto principal. Além disso, é um mercado bastante competitivo, no qual a pessoa pode escolher o revendedor entre os diversos estabelecimentos próximos, podendo a localização geográfica influenciar muito na decisão de compra.

Segundo a Agência Nacional do Petróleo, Gás Natural e Biocombustíveis - ANP (2010), existem 447 postos revendedores de combustíveis automotivos no Distrito 
Federal, e pouco se sabe sobre quais são os aspectos, realmente, relevantes para a escolha do estabelecimento pelo consumidor. Os gestores têm dificuldades para identificarem a atratividade dos diversos serviços oferecidos nesses estabelecimentos.

Identificar a quantidade de clientes de uma empresa é um grande desafio, entretanto, é importante já que permite aos seus gestores um maior conhecimento sobre seu desempenho no mercado.

A pergunta desta pesquisa é: Qual a influência do benefício utilitário, benefício informativo e preço na quantidade de clientes, lucro e receita proveniente da venda de combustíveis automotivos?

\subsection{Objetivo Geral}

Investigar a influência do benefício utilitário, benefício informativo e preço sobre a quantidade de clientes, receita e lucro oriundo da venda de combustíveis automotivos.

\subsection{Objetivos Específicos}

a) Analisar a relação preditiva do preço, benefício utilitário e informativo sobre indicadores de performance no mercado relacionada a quantidade de clientes, receita e lucro proveniente da venda de combustíveis;

b) Analisar a relação preditiva do preço, benefício utilitário e informativo sobre indicadores de desempenho do próprio estabelecimento relacionada a quantidade de clientes, receita oriunda da venda de combustíveis e lucro proveniente da venda de combustíveis. 


\subsection{Justificativa}

A partir da pesquisa da influência das estratégias de Marketing na quantidade de clientes, receita e lucro proveniente da venda de combustíveis de uma revendedora de combustíveis automotivos pelo consumidor é possível identificar quais estratégias de Marketing são mais influentes na quantidade de clientes, receita e lucro proveniente da venda de combustíveis. Cientificamente, isso é importante por auxiliar a avançar na compreensão de como ocorre o processo de escolha do consumidor, que é tido como complexo, principalmente, por se tratar de um produto de baixo envolvimento. Logo, permite compreender melhor como as empresas podem influenciar nas atividades do consumidor. No sentido gerencial, é essencial para que se possa avaliar a efetividade dos serviços desse segmento, evitando o dispêndio desnecessário de dinheiro em atividades pouco valorizadas pelo seu consumidor. Todas as estratégias são estudadas ao mesmo tempo, a fim de que se possa identificar as que mais influenciam na quantidade de clientes, receita e lucro proveniente da venda de combustíveis em revendedores de combustíveis automotivos. A partir desse estudo foi possível identificar em quais atividades devem-se concentrar os esforços financeiros, por elas estarem relacionadas ao aumento da quantidade de clientes do segmento estudado. 


\section{REFERENCIAL TEÓRICO}

Nesse trabalho estudou-se o mercado de revendedores de combustível no Distrito Federal. Para tanto, buscou-se entender os indicadores de desempenho utilizados pelas empresas em geral, já que estas são responsáveis para se entender a performance da empresa e traçar ações corretivas. Uma das maneiras de se aumentar o desempenho das empresas é traçando-se boas estratégias de marketing, capazes de aumentar o número de clientes e rentabilidade da empresa. Logo, foram estudadas as principais estratégias de Marketing relacionadas ao aumento da quantidade de clientes, lucro proveniente da venda de combustíveis e receita oriunda da venda de combustíveis. Todos estes aspectos são necessários para entender o mercado abordado no trabalho.

\subsection{Indicadores de desempenho}

Os indicadores de desempenho organizacionais são utilizados pelos gestores para mensurar a performance da empresa e auxiliar na tomada de ações corretivas, a fim de melhorar a atuação da empresa no seu mercado. Segundo Fishmann e Zilber (1999), os sistemas de medidas de desempenho devem ser entendidos como uma parte fundamental do controle da administração.

Segundo Icó e Braga (2001), existem dois tipos de indicadores de desempenho, os absolutos, que são medidas absolutas, financeiras ou não financeiras, como o lucro; e os relativos, que são o resultado da comparação entre duas medidas (estes também podem ser financeiros ou não financeiros e podem ser exemplificados pelo volume de vendas). No estudo de Miranda, Wanderley, Meira e Silva (2002), eles observaram que a maior parte dos indicadores utilizados pelas empresas é de caráter financeiro. Desses predominavam os relacionados ao faturamento e os indicadores relacionados ao lucro também são analisados na pesquisa.

Os analistas observam diversos indicadores de desempenho para terem informações mais completas sobre as empresas, já que a análise dos dados sem contexto pode levar ao erro. Um exemplo disso é o aumento da receita, que não 
significa, necessariamente, um bom desempenho financeiro, pois caso ocorra juntamente com um aumento das despesas poderá não resultar em um aumento dos lucros. Como no estudo de Laranjeiras (2003), no qual foram estudadas as principais operadoras de telefonia, percebe-se que estas, apesar de terem um crescimento expressivo na receita, tiveram uma redução no lucro.

Pasa e Shugan (2001) sugerem que empresas com vantagens mercadológicas têm maiores potenciais de lucro. Day e Wensley afirmam que para uma performance superior é necessário um ganho de mercado e uma vantagem em relação aos competidores. A maior recompensa é o domínio do market-share (participação de mercado de uma empresa) e lucratividade acima da média de mercado.

Para calcular o desempenho da marca, Ehenberg, Uncles e Goodhardt (2004) sugerem o market-share, penetração de mercado, lealdade e troca de marca. Segundo os autores, o primeiro é a relação entre todas as compras da marca e todas as compras da categoria. A segunda é a relação entre a quantidade de consumidores que compraram a marca pelo menos uma vez e o número de clientes potenciais. A terceira é a relação entre as vezes que o consumidor comprou a marca e a média de vezes que ele comprou a categoria. Já a última é a quantidade de vezes, em percentual, que o consumidor comprou outra marca. Para Ehrenberg, Uncles e Goodhardt (2004) pode-se determinar as vendas de uma marca pelo número de consumidores que compram essa marca, pela frequência de compra dessa marca e pela frequência de compra de outras marcas.

Hauser e Shugan (1983) sugerem que os gestores devem olhar os lucros tanto quanto as vendas, pois o potencial lucrativo do mercado diminuiu com o aumento da competição.

Existem diversos fatores responsáveis por mudanças nos indicadores de desempenho. Segundo Keng e Ehrenberg (1984), a quantidade de vendas e marketshare podem ser influenciadas por fatores referentes ao local de consumo, tais como: as diferenças relacionadas à localização, estilo do proprietário, variedade de produtos e marcas ofertadas, precificação, políticas promocionais, características do produto, características do consumo; podem, ainda, serem relacionadas a aspectos do consumidor, como: as diferenças de hábitos, estilo de vida, proximidade do estabelecimento, experiência proporcionada pelo produto ou serviço, exposição a propagandas. 
Segundo Wright (1975), a grande conquista de um programa de Marketing é induzir a compra de um produto ou serviço, dentre as diversas opções disponíveis. Portanto, deve-se compreender as variáveis que maximizam os benefícios da alternativa para que esta seja priorizada em detrimento das outras opções.

Para mensurar ou avaliar a eficácia da organização, pode-se utilizar a quantidade de clientes de uma determinada empresa, a qual pode ser determinada pela quantidade de comportamentos de compra que ocorrem nessa empresa, já que a quantidade de clientes influencia diretamente no aumento da receita. Ehenberg, Uncles e Goodhardt (2004) afirmam que a diferença entre uma marca grande ou pequena está na quantidade de clientes e em quão leal eles sejam. Declaram, ainda, que em geral as vendas são fortemente influenciadas pelos padrões de comportamento do consumidor. Portanto, para entender a quantidade de clientes, deve-se entender o consumidor e seu comportamento de compra. Esse comportamento é diferenciado de acordo com a complexidade e envolvimento do consumidor.

Cada compra possui aspectos diferenciados em relação ao comportamento
do consumidor. O comportamento de compra de uma pasta dental, por
exemplo, difere muito do comportamento envolvido na compra de um
automóvel zero-quilômetro. As decisões poderão ser mais ou menos
complexas, envolvendo a necessidade maior ou menor da quantidade de
informação, por serem compras pontuais, que envolvem maior risco, e são
expressivas, além de haver diferenças significativas entre as marcas dos
produtos. (SAMARA; MORSCH, 2006, p.23) No modelo de perspectiva comportamental de Foxall (1966), observa-se que para o comportamento de consumo aconteça, o consumidor utiliza informações presentes no cenário de consumo, assim como o seu histórico de aprendizagem. A situação de consumo é representada pelo cruzamento desses dois fatores, os quais são responsáveis pelo comportamento de consumo. Após o consumo Foxall (1998) aponta como consequências o benefício utilitário, o benefício informativo e aversivas. O primeiro está relacionado ao benefício funcional do bem consumido; o segundo aos feedbacks recebidos devido ao consumo, ou seja, resultados das interações sociais; já o terceiro quando acontece diminui a chance da repetição do consumo devido às punições utilitárias e punições informativas, essa situação pode ser exemplificada pela não satisfação dos atributos funcionais do bem ou pelo feedback negativo recebido em interações sociais. As três consequências do ato de consumo podem aumentar ou diminuir a probabilidade de ocorreência do mesmo comportamento no futuro. 


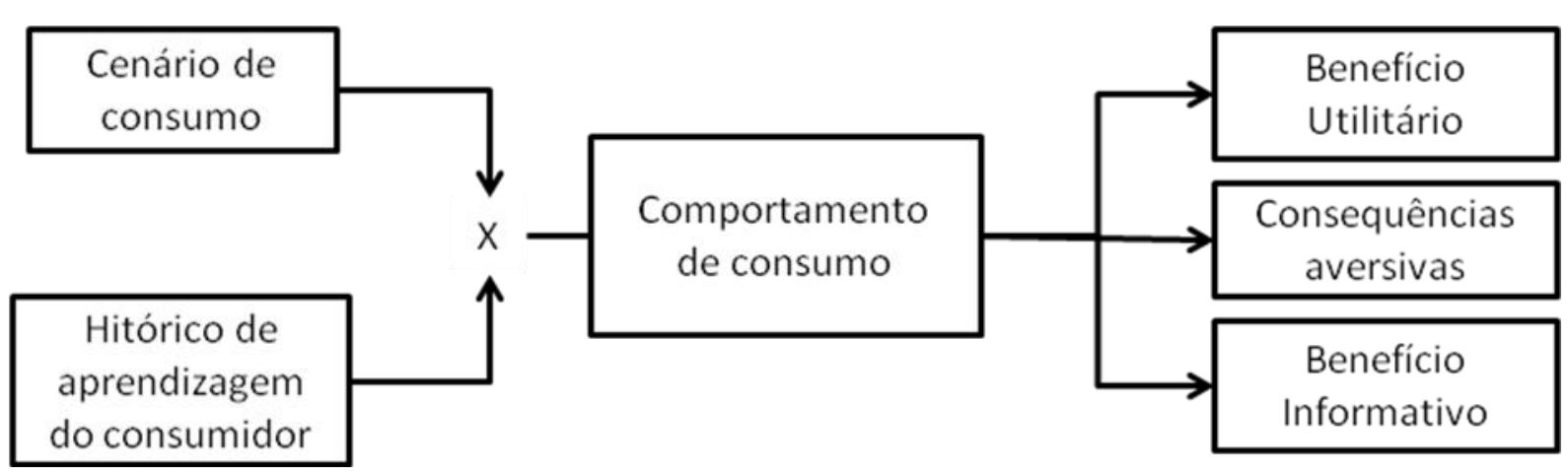

Figura 1: Modelo de perspectiva comportamental, tradução nossa (FOXALL, 1998)

O cenário de consumo e o histórico de aprendizagem apresentam influências diferentes no ato da compra. Ambos são importantes para se entender o comportamento de consumo. Segundo Porto (2009), a identificação os mecanismos de escolha do consumidor é uma maneira de predizer o que leva o consumidor a fazer a compra da marca em detrimento de outra marca. Ehenberg, Uncles e Goodhardt (2004) afirmam que as mudanças em preço, fórmula do produto e distribuição mudam pouco a lealdade do cliente, mas afetam a penetração de mercado, o market-share e o volume de vendas. Portanto, deve-se identificar o que é valorizado pelo consumidor no cenário de consumo, como influenciar no histórico de aprendizagem do mesmo, para identificar as estratégias de Marketing mais efetivas.

\subsection{Estratégias de Marketing}

O Marketing dá suporte à missão e à visão da empresa e transformá-las em objetivos e metas palpáveis, além de serem claras e práticas para a tomada de decisão. As estratégias de Marketing são o meio traçado pela empresa para atingir um bom desempenho. Segundo Porto (2009), o gestor lida, diariamente, com situações no qual tem que priorizar a estratégia de Marketing a ser implementada. Logo, é fundamental para o gestor identificar a estratégia mais preditora do comportamento de escolha de marcas no ponto-de-venda.

Segundo Ferrel, Hartline e Lucas (2002), a estratégia de Marketing está relacionada a selecionar um mercado e fazer decisões sobre elementos do produto, preço, promoção e distribuição. Além disso, segundo Semenik e Bamossy (1995), uma das 
funções do Marketing é facilitar a troca, e o preço é um componente que estabelece o valor dessa troca, no qual o cliente troca um valor monetário pelos valores agregados ao produto que deseja.

Segundo Day e Wensley (1988), para uma empresa diferenciada ser lucrativa, os clientes devem estar dispostos a pagar um preço premium pelos benefícios ofertados. A diferença desse estabelecimento para um estabelecimento comum é uma prestação de serviços superior, é ter uma marca forte e oferecer características inovadoras.

Thomas, James e Lomax (1998), ao estudarem o potencial de carros movidos a hidrogênio, observaram que a penetração desses carros no mercado depende diretamente do preço desses em relação aos demais modelos e ao preço do hidrogênio em relação aos demais combustíveis. Peters Filho (2003), ao estudar restaurantes finos em São Paulo, observou que o preço desses estabelecimentos é visto como um aspecto negativo à experiência proporcionada pelo restaurante, a ida a esses estabelecimentos e para minimizar o efeito negativo do preço essas empresas deveriam maximizar os outros atributos a fim de que os consumidores se atentem menos ao preço. A partir desses estudos é possível concluir que o preço pode ser visto como um dos responsáveis pela quantidade de clientes de empresas. Grewal, Krishnan, Baker, e Borin (1998) observaram que apesar dos descontos de preços gerarem um maior tráfego na loja, esses descontos têm um efeito negativo na percepção de qualidade e referências internas de preço, além disso, é possível que esses descontos possam interferir negativamente na imagem da empresa.

Essa imagem pode ser descrita como a marca. "Marca é um nome, termo, sinal, símbolo, desenho ou uma combinação dos mesmos, que pretende identificar os bens e serviços de um vendedor ou grupo de vendedores e diferenciá-los daqueles dos concorrentes" (American Marketing Association, 1960, apud Pinho, 1996, p.14).

Segundo Caputo, Marcedo e Nogueira (2008), um dos grandes responsáveis pela geração de valor das empresas tem sido os ativos intangíveis, e o mais importante deles é a marca. Isso porque, além dos ativos tangíveis poderem ser copiados, podem se tornar obsoletos facilmente com os avanços tecnológicos, ao contrário dos ativos intangíveis, que são mais difíceis de serem copiados.

De acordo com Anderson (1974), apesar de ainda frágil, a preferência por marcas reduz a importância do preço nas alternativas de compra do consumidor. Logo, com 
a preferência por marcas, alguns atributos passam a ser mais valorizados pelo consumidor que o preço pelo produto. Dodds e Monroe (1985) estudaram a compra de walkman da marca Sony e observaram em seu estudo que utilizar o nome da marca aumenta a percepção de qualidade e propensão a compra nos produtos por eles estudados.

Aaker (1998) apud Caputo, Macedo e Nogueira (2008) afirmam que a marca é capaz de influenciar as avaliações dos clientes e serviços. Já Grewal, Krishnan, Baker e Borin (1998) observaram em seu estudo que os respondentes classificados como mais informados têm sua decisão de compra fortemente influenciada pelo nome da marca. O que mostra como a marca tem se tornado um atributo relevante na situação de consumo.

O produto é o principal na estratégia de Marketing. É importante ter em
mente que produto significa mais que bens tangíveis. Produtos é a
combinação de bens, serviços, idéias e até pessoas. A melhor forma de
observar o produto é como um conjunto de recursos e vantagens que tem
que ter a capacidade de satisfazer as necessidades e desejos do
consumidor, além de entregar os benefícios valorizados. (FERREL,
HARTLINE; LUCAS, 2002, p.109)

Rathmell (1966) apresenta como características de serviços o fato de eles não serem estabelecidos por meio de preço e sim por meio de taxas e cobranças. 0 valor a ser cobrado varia bastante, podendo ser impostas pelo governo ou reguladas pelo mercado. Além disso, se comprar um serviço, o comprador não pode utilizar o serviço como deseja, deve-se respeitar alguns preceitos do vendedor. Como os serviços são atos ou processos, estes são consumidos assim que produzidos, apesar de serem customizados para cada cliente. Para um determinado serviço existe um processo igual para todos. Os serviços entre são bastante diferenciados entre eles, têm sistemas de Marketing bem específicos e outro aspecto relevante é que o simbolismo deriva da performance e não da posse.

Segundo Peters Filho (2003), os serviços possuem como característica o fato de só poderem ser avaliados após a compra e durante o consumo ou produção. Por isso, há um maior risco assumido pelos clientes. No estudo de Boulding, Kalra, Staelin e Zeithaml (1993) foi possível concluir que a percepção de qualidade dos serviços aumenta a intenção de compra dos consumidores.

Andrade (2004) percebeu ao estudar hotéis que estes não têm utilizado todo o potencial dos aspectos tangíveis como ferramenta para obter vantagem competitiva, 
apesar da consciência dos gerentes que estes aspectos influenciam bastante 0 consumidor. Já em relação aos funcionários, Andrade (2004) observa que estes influenciam bastante a qualidade percebida pelo cliente. De forma geral, o cenário de serviços que comunica bem a imagem do hotel e tem uma resposta desejada pelos hóspedes pode afetar as vendas. No caso de serviços deve-se, então, explorar os aspectos tangíveis a fim de se estimular o consumo.

Outro aspecto bastante influente na prestação de serviços ou venda de produtos é a localização. De acordo com Dudley (1990), a localização das empresas pode influenciar os padrões de comportamento de busca dos consumidores, visto que estes acham mais conveniente comparar as ofertas de empresas que estão localizadas em suas proximidades. Isto aplica-se às empresas, as quais se deva visitar para se ter uma tomada de preço.

\begin{abstract}
O desempenho de supermercados depende, grandemente, de sua localização, pois a maior parte das vendas de uma loja vem de clientes que moram dentro de uma área geográfica relativamente pequena em torno da loja. Não é surpresa, portanto, que os estudos varejistas venham dando tanto destaque ao conceito de área de influência. Ao investigar onde os clientes estão localizados, esse conceito permite identificar a dimensão geográfica da demanda de mercado disponível para certa loja. No varejo, essa dimensão geográfica é uma variável pouco controlável, pois as lojas não conseguem determinar os limites geográficos de onde se originam seus clientes. (PARENTE; KATO, 2001, p. 1)
\end{abstract}

Estar próximo aos concorrentes não é necessariamente negativo. No estudo de Dudley (1990) ele sugere que no caso de competição intensa as empresas devem evitar estar próximas aos seus concorrentes, porém há casos em que as empresas podem ser parceiras para atrairem um número maior de clientes, que poderá ser mais benéfico para as empresas que se estas não estivessem próximas. Segundo Masano (2003) apud Neves e Costa (2008), a boa localização é o lugar de maior fluxo de clientes, pois estes poderão lembrar do estabelecimento, quando precisarem do produto.

Aspectos como marca, serviços oferecidos, preço e localização influenciam o comportamento do consumidor e como consequência a quantidade de clientes de um estabelecimento. Para mensurar a quantidade de clientes é necessário entender como cada um desses aspectos influência o consumo no mercado de revendedores de combustível. 


\subsection{Mercado de revendedores de combustível}

O combustível automotivo é um produto que tem um baixo envolvimento com o consumidor, porque ele, em poucas vezes, chega a ter um contato direto com o produto, o qual sai da bomba do posto e vai direto para o reservatório do carro, $\mathrm{O}$ produto também tem aspectos no tato e olfato desagradáveis aos consumidores. Além disso, o combustível em si é um produto de difícil avaliação pelo consumidor, pois este não possui os conhecimentos técnicos necessários para esta avaliação. Portanto, o consumidor utiliza para a avaliação do combustível os serviços periféricos do revendedor como demonstrado por Oliver (1997) apud Netherlands (2000) que afirma que em um revendedor de combustível a disponibilidade de combustível é uma obrigação, manter banheiros limpos são satisfatórios e os serviços são prazerosos.

Os consumidores de combustível automotivo não possuem conhecimento
técnico para avaliar qual produto é mais adequado para consumo. Um dos
fatores que balizam essa afirmação é a complexidade da composição do
combustível. Outro aspecto é comportamental: não existe hábito de
consultar os manuais dos produtos, como no caso dos automóveis, por
grande parte dos consumidores brasileiros. Consequentemente,procuram
avaliar o produto de acordo com os atributos que consideram mais
relevantes, como a "qualidade" e a "marca", que no caso de combustível
automotivo, são, praticamente, equivalentes. A "marca" sobressai por ter,
embutida em seu significado, a qualidade do produto. A falta de
conhecimento técnico para julgar a qualidade do combustível conduz o
consumidor a avaliar as marcas como garantia da qualidade, e o faz através
da experimentação ou por indicação de terceiros, como no caso da
propaganda boca-a-boca. (LIMA, 2008 p.97)

Outro aspecto relevante é que, segundo Netherlands, alguns elementos que inicialmente são prazerosos, podem ser institucionalizados pelo consumidor e virar um elemento satisfatório como o fato de nos Estados Unidos o consumidor poder passar o cartão de crédito na bomba de combustível, evitando sair do lugar e de possivelmente pegar fila. Isso mostra que mesmo em um contexto de abastecimento diferente, a forma de pagamento pode influenciar a compra.

Os revendedores de combustível podem ter marca própria ou apresentarem a marca da distribuidora. Segundo a cartilha da Agência Nacional do Petróleo, Gás Natural e Biocombustíveis (ANP, 2008), uma das obrigações do revendedor de combustível é a de informar ao consumidor a origem do combustível comercializado. Este revendedor pode ser bandeirado, ou seja, exibir a marca do distribuidor e pode 
vender somente combustível desse distribuidor ou bandeira branca. Nesta o revendedor não é obrigado a comercializar o combustível de nenhum revendedor fixo, contudo, é obrigatório que o distribuidor fornecedor apareça de forma visível em cada uma das bombas. Os revendedores bandeira branca têm conquistado cada vez mais o mercado de revendedores de combustível. Segundo a ANP, entre novembro de 2009 e abril de 2010 os postos bandeira branca tiveram uma participação expressiva; em gasolina eles representavam 39,54\%, em óleo diesel eles representavam 36,54\% e em etanol eles representavam 39,36\%. As não conformidades para gasolina estão relacionadas à destilação, octanagem, etanol, aspecto, cor e benzeno; para o óleo diesel são observados: corante, aspecto, pt. Fulgor, enxofre, t. Biodiesel, cor astm, mass. Específica e destilação; para o etanol são observados mass. Específ/TA, condutividade, $\mathrm{PH}$, aspecto e cor. Apesar destes não serem os revendedores com maior nível de estabelecimentos em não conformidade, eles estavam sempre maior que a média nacional. O que faz com que os consumidores possam não confiar na qualidade dos combustíveis.

Segundo Boletim de Qualidade dos combustíveis (20010), no Distrito Federal em $2009,1,8 \%$ dos revendedores não estavam com a gasolina em conformidade, em relação ao álcool; o percentual foi de $0,3 \%$ e não houve não conformidade quanto ao oléo diesel. É possível perceber que no Distrito Federal não há uma quantidade grande de revendedoras que apresentem problemas, sendo que em alguns combustíveis há um percentual inferior à média nacional, A gasolina possui 1,4\% de estabelecimentos fora de conformidade, o álcool 3,1\% e o óleo diesel 2,4\%.

Em relação ao preço do combustível, há uma alta tributação. Segundo a Fecombustíveis (2009), a tributação da gasolina é de $42 \%$, a do álcool de $18,4 \%$ e a do óleo diesel $23 \%$. Outro aspecto importante é o preço dos combustíveis em conformidade e fora de conformidade. Em alguns combustíveis o preço médio, quando está fora de conformidade, é maior que quando este está em conformidade. Essa relação pode ser observada na figura 2, elaborado com base no Boletim de Qualidade dos Combustíveis Automotivos, ANP (2010). Isso significa que nesse mercado nem sempre preço pode ser utilizado como sinônimo de qualidade. 


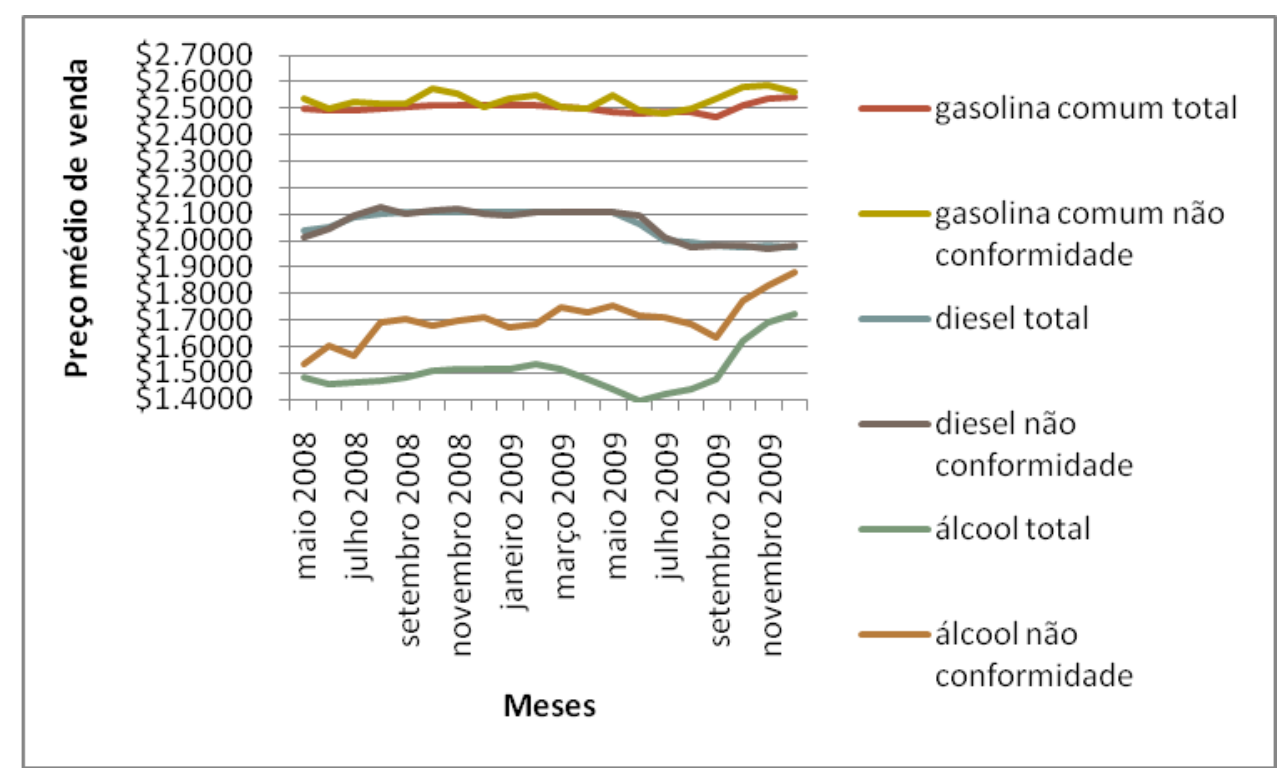

Figura 2: Preço de combustíveis em conformidade e em não conformidade, autoria própria.

O mercado de revendedoras de combustível é bastante particular por ser um produto de baixo envolvimento, de difícil avaliação e no qual o preço não pode ser utilizado como um padrão de qualidade, porém a marca do revendedor ou do combustível pode ser considerada um atributo para se avaliar qualidade. Além disso, os serviços oferecidos pelo revendedor podem ser um atrativo de clientes. 


\section{MÉTOdOS E TÉCNICAS DE PESQUISA}

\subsection{Tipo e descrição geral da pesquisa}

Trata-se de uma pesquisa quase experimental. Segundo Cozby (2009), nesse tipo de pesquisa o pesquisador não possui o mesmo grau de controle que em pesquisas experimentais. Foram utilizados dados secundários organizados em forma de painel, dados de 16 postos de uma mesma rede de revendedores de combustíveis automotivos entre 2007 e 2010.

\subsubsection{Modelo empírico do projeto}

Foram observada a influência do benefício utilitário, benefício informativo e preço, na receita relativa, lucro relativo e quantidade de clientes de 16 revendedoras de combustíveis na quantidade de clientes, conforme figura 3.

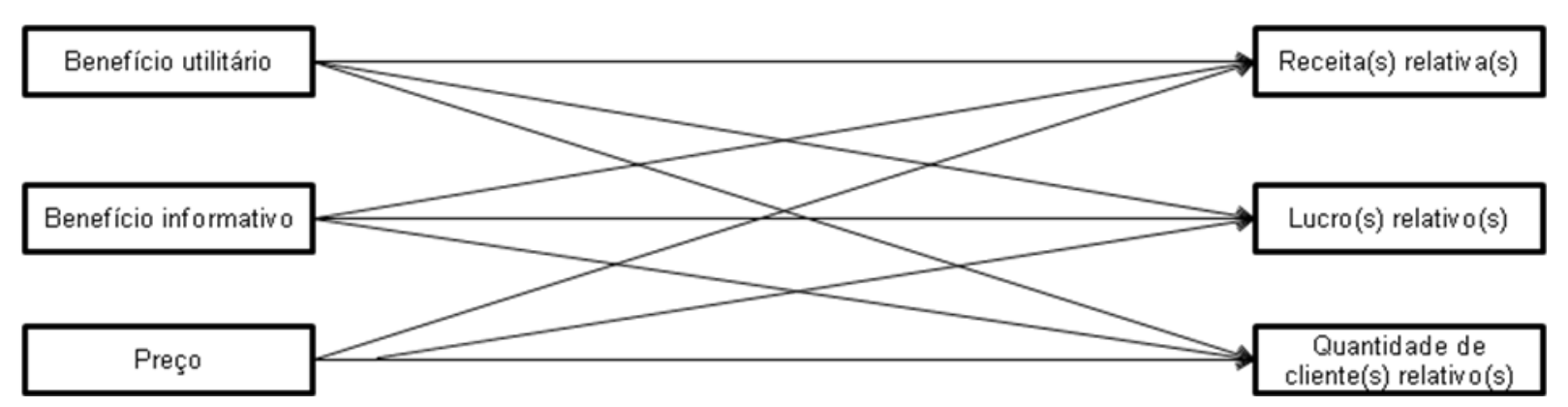

Figura 3: modelo da metodologia, autoria própria

As variáveis dependentes foram analisadas conforme com o quadro 1, no qual os dados foram distribuídos conforme com preço médio e a quantidade de concorrentes.

\begin{tabular}{|c|l|l|}
\hline $\begin{array}{c}\text { Preço do } \\
\text { estabelecimento } \\
\text { menor que } a \\
\text { média }\end{array}$ & $\leq 3$ concorrentes & $\mathrm{y}(\mathrm{r}, \mathrm{l}, \mathrm{cl})_{\mathrm{\alpha}}=\mathrm{a}+\mathrm{bx}(\mathrm{pr})+\mathrm{bx}(\mathrm{bu})+\mathrm{bx}(\mathrm{bi})$ \\
\cline { 2 - 4 } & $>3$ concorrentes & $\mathrm{y}(\mathrm{r}, \mathrm{l}, \mathrm{cl})_{\beta}=\mathrm{a}+\mathrm{bx}(\mathrm{pr})+\mathrm{bx}(\mathrm{bu})+\mathrm{bx}(\mathrm{bi})$ \\
\hline $\begin{array}{c}\text { Preço do } \\
\text { estabelecimento } \\
\text { maior que } \mathrm{a} \\
\text { média }\end{array}$ & $\leq 3$ concorrentes & $\mathrm{y}(\mathrm{r}, \mathrm{l}, \mathrm{cl})_{\mathrm{Y}}=\mathrm{a}+\mathrm{bx}(\mathrm{pr})+\mathrm{bx}(\mathrm{bu})+\mathrm{bx}(\mathrm{bi})$ \\
\cline { 2 - 3 } & & $\mathrm{y}(\mathrm{r}, \mathrm{l}, \mathrm{cl})_{\bar{\delta}}=\mathrm{a}+\mathrm{bx}(\mathrm{pr})+\mathrm{bx}(\mathrm{bu})+\mathrm{bx}(\mathrm{bi})$ \\
\hline
\end{tabular}

Quadro 1: modelo da metodologia, autoria própria.

Sendo que r é receita relativa, I é lucro relativo, cl é quantidade de clientes, pr é preço, bu é benefício utilitário e bi é benefício informativo. 


\subsubsection{Conceitos e variáveis}

No trabalho foi mensurado o efeito das seguintes variáveis na quantidade de clientes, lucro e receita:

a) benefício utilitário: Segundo Foxall (1997) estes são todos os benefícios (benefício) referentes aos atributos funcionais, materiais, do valor de uso adquiridos por meio da posse, uso ou compra de um bem ou serviço. Para montar a variável independente benefício utilitário foram utilizadas as estratégias de serviços de revendedores de combustível. Serviços são caracterizados por Rathmell (1966) como, além de outras características, atos ou processos, que são consumidos assim que produzidos, apesar de serem customizados para cada cliente. Estes foram mensurados por meio de visitas aos estabelecimentos estudados e conversas com os gestores. Os serviços ofertados pela rede estudada eram: lavagem de carro, loja de conveniências, troca de óleo, lanchonete Giraffas e loja de carros usados, todos esses serviços tem o mesmo peso no benefício utilitário.

b) benefício informativo: Segundo Foxall (1997), o benefício informativo é simbólico, relativo às reações dos observadores, aos feedbacks recebidos devido ao consumo, ou seja, resultado das interações sociais de forma a manter o comportamento (benefício). Para montar a variável independente benefício informativo foram utilizadas as marcas dos revendedores de combustível. "Marca é um nome, termo, sinal, símbolo ou desenho, ou uma combinação dos mesmos, que pretende identificar os bens e serviços de um vendedor ou grupo de vendedores e diferenciá-los daqueles dos concorrentes" (American Marketing Association, 1960, apud PINHO, 1996, p.14). Esta foi mensurada por visita aos estabelecimentos e conversas com os gestores, pois alguns dos estabelecimentos estudados mudaram a sua marca no período estudado. As marcas observadas no estudo foram: BR, Texaco, Ipiranga e Gasolline. Com base na publicação do Top of Mind do Jornal de Brasília (2009), os três primeiros foram considerados como alto benefício informativo e o último como baixo benefício informativo.

c) estratégia de preço de revendedores de combustível: segundo Semenik e Bamossy (1995), preço é um componente que estabelece o valor dessa troca, na qual o cliente troca um valor monetário pelos valores agregados ao produto 
que deseja. Este foi mensurado através de dados históricos obtidos nos relatórios da empresa que indicavam o preço vendido na bomba, diariamente. Para efetuar, foram utilizadas duas medições de preços, a variação do preço que é o preço do combustível em um determinado estabelecimento dividido pelo preço médio de todos os dias do mesmo estabelecimento - e o preço em relação à média do mercado, que é o preço do combustível em um determinado dia dividido pelo preço médio de todos os postos em todos os dias. Este preço foi dicotomizado, gerando o preço acima ou abaixo da média de mercado. $\mathrm{O}$ preço médio foi calculado a partir da média de todos os combustíveis ofertados em todos os revendedores de combustível nos dias observados e o resultado foi de $R \$ 2,28$ e desvio padrão de 0,08 , a partir desse valor foi analisado se os preços médios diários dos estabelecimentos estavam acima ou abaixo dessa média de mercado;

d) localização dos concorrentes dos revendedores de combustível: Localização é o espaço geográfico no qual a organização se encontra. A localização dos concorrentes foi mensurada pelo Google Maps, no qual foram identificados todos os postos que se encontravam no raio de $1,5 \mathrm{~km}$ dos postos estudados. Após isso, estes foram dicotomizados em estabelecimentos com $\leq 3$ concorrentes ou > 3 concorrentes;

e) receita relativa: A receita nesse caso é proveniente apenas da venda de combustíveis automotivos; ela foi dividida em dois tipos: a receita relativa ao mercado e relativa ao próprio posto;

f) lucro relativo: Referente apenas à venda de combustível, ele é calculado subtraindo-se o preço de custo do preço de venda; ele foi dividido em dois tipos: o lucro relativo ao mercado e relativo ao próprio posto;

g) quantidade de clientes relativo: Refere-se ao número de abastecimentos ocorridos relativo ao mercado e ao próprio posto. 


\subsection{Caracterização da organização, setor ou área do objeto de estudo}

Segundo a Agência Nacional do Petróleo, Gás Natural e Biocombustíveis - ANP (2010) existem 447 revendedores de combustível no Distrito Federal. Sendo 202 revendedores da bandeira Petrobrás, 108 revendedores Bandeira Branca e os demais com as bandeiras Ale, Shell, Texaco e Esso. Foi estudada uma rede de revendedora de combustíveis possuidora de 16 postos. Esta rede foi criada em 1999 por três sócios. Possui revendedores bandeirados e com marca própria, Gasolline. O foco da pesquisa é a venda de combustíveis de forma diária.

\subsection{População e amostra}

A amostra possui dados de 16 estabelecimentos, entre 15/10/2007 e 30/06/2010, sendo que o revendedor com mais dias de observação possui 990 dias e o com menos dias de observação possui 461 dias. Totalizando 12854 observações. Para alguns estabelecimentos se tem os dados desde o dia da sua criação, para outros se tem os dados apenas de uma amostra de dias. Para o cálculo da amostra foi feito um teste $F$ para análise de regressão múltipla. Para tanto, foi feito um teste do poder de análise em que o tamanho do efeito é igual a 0,02 com $\alpha=0,05$ e com poder de 95\% com 3 preditores, que são representadas pelo preço de combustíveis, benefício utilitário e benefício informativo. O estabelecimento mais antigo estudado possui 10 anos de existência, dos quais 825 dias foram observados. Esse revendedor, que poderia representar maiores chances de apresentar Erro Tipo 2, apresentou-se satisfatório, com poder amostral de 94\%, conforme pode ser visto na 
figura 4.

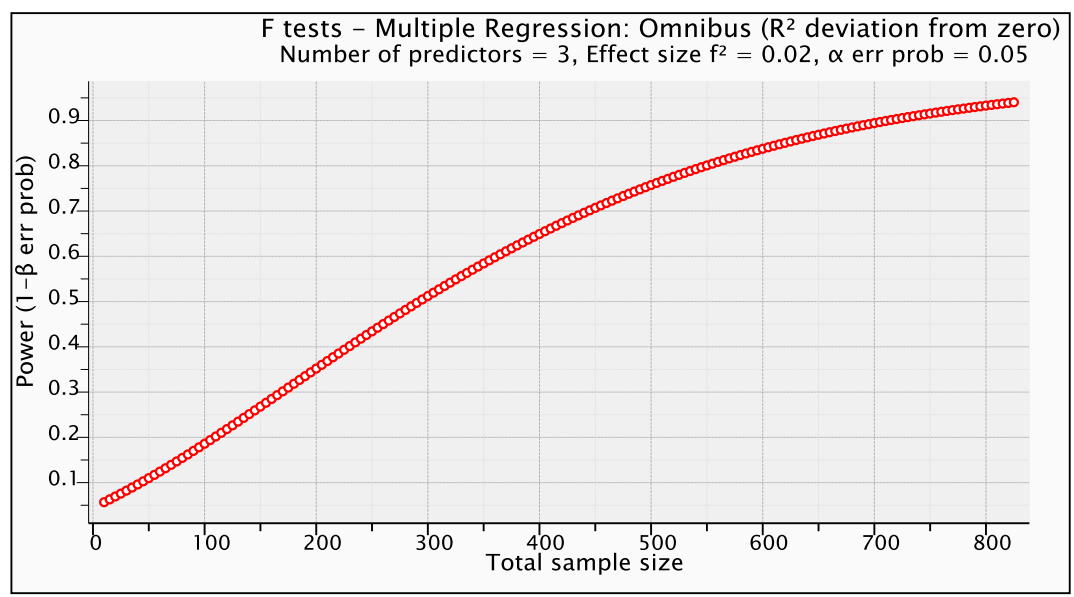

Figura 4: Teste do poder da análise

$\mathrm{Na}$ amostra de postos que apresentaram diferentes níveis de benefício utilitário foram observados os seguintes serviços oferecidos nos revendedores de combustível: lavagem de carros, loja de conveniências, troca de óleo, lanchonete Giraffas e loja de carros usados. Cada um dos itens tem representabilidade de peso igual no benefício utilitário, sendo que para o cálculo dele o estabelecimento podia não ter nenhum serviço, ou seja, ter benefício utilitário 0 ou ter todos serviços, tendo benefício utilitário 5 .

A tabela 1 mostra como a amostra estava dividida quanto à existência dos serviços nos revendedores de combustível, no qual são apresentados o percentual de dias observados com esses serviços nas situações pré-determinadas.

Tabela 1: divisão da amostra quanto aos serviços oferecidos

\begin{tabular}{l|l|l|l|l|l|l}
\cline { 3 - 7 } & \multicolumn{2}{c|}{$\begin{array}{l}\text { Lavagem } \\
\text { de carros }\end{array}$} & $\begin{array}{l}\text { Loja de } \\
\text { conveniências }\end{array}$ & $\begin{array}{l}\text { Troca de } \\
\text { óleo }\end{array}$ & $\begin{array}{l}\text { Lanchonete } \\
\text { Giraffas }\end{array}$ & $\begin{array}{l}\text { Loja de carros } \\
\text { usados }\end{array}$ \\
\hline $\begin{array}{l}\text { Preço do } \\
\text { estabelecimento menor } \\
\text { que a média do } \\
\text { mercado }\end{array}$ & $\leq 3$ concorrentes & $96.6 \%$ & $96.6 \%$ & $63.8 \%$ & $0 \%$ & $0 \%$ \\
\hline $\begin{array}{l}\text { Preço concorrentes } \\
\text { estabelecimento maior } \\
\text { que a média do } \\
\text { mercado }\end{array}$ & $100 \%$ & $51.3 \%$ & $80.1 \%$ & $23.4 \%$ & $18 \%$ \\
\cline { 2 - 8 } & $>3$ concorrentes & $100.0 \%$ & $54 \%$ & $69.7 \%$ & $0 \%$ & $0 \%$ \\
\hline
\end{tabular}


$\mathrm{Na}$ amostra de postos, que apresentaram diferentes níveis de benefício informativo, foram observados estabelecimentos com as bandeiras Gasolline, BR, Ipiranga e Texaco. Segundo a pesquisa Top of Mind do Jornal de Brasília (2009), na categoria distribuidora de combustível as marcas estudadas apareceram na seguinte ordem: BR, Texaco, Ipiranga e Gasolline; devido a esse estudo as marcas BR, Ipiranga e Texaco foram consideradas como sendo de alto benefício informativo e Gasolline de baixo benefício informativo. A amostra estava dividida conforme a tabela 2 .

Tabela 2: divisão da amostra quanto ao benefício informativo

\begin{tabular}{|c|c|c|c|c|c|}
\hline \multirow{7}{*}{$\begin{array}{c}\text { Preço do } \\
\text { estabelecimento } \\
\text { menor que a média } \\
\text { do mercado }\end{array}$} & \multirow{4}{*}{$\leq 3$ concorrentes } & $\begin{array}{c}\text { Benefício } \\
\text { informativo baixo }\end{array}$ & Gasolline & $68.8 \%$ & $68.8 \%$ \\
\hline & & \multirow{3}{*}{$\begin{array}{c}\text { Benefício } \\
\text { informativo alto }\end{array}$} & $\mathrm{BR}$ & $2.1 \%$ & \multirow{3}{*}{$31.2 \%$} \\
\hline & & & Ipiranga & $21.7 \%$ & \\
\hline & & & Texaco & $7.3 \%$ & \\
\hline & \multirow{3}{*}{$>3$ concorrentes } & $\begin{array}{c}\text { Benefício } \\
\text { informativo baixo }\end{array}$ & Gasolline & $66.3 \%$ & $66.3 \%$ \\
\hline & & \multirow{2}{*}{$\begin{array}{c}\text { Benefício } \\
\text { informativo alto }\end{array}$} & $\mathrm{BR}$ & $10.3 \%$ & \multirow{2}{*}{$33.7 \%$} \\
\hline & & & Texaco & $23.4 \%$ & \\
\hline \multirow{6}{*}{$\begin{array}{l}\text { Preço do } \\
\text { estabelecimento } \\
\text { maior que a média } \\
\text { do mercado }\end{array}$} & \multirow{4}{*}{$\leq 3$ concorrentes } & $\begin{array}{c}\text { Benefício } \\
\text { informativo baixo }\end{array}$ & Gasolline & $64.1 \%$ & $64.1 \%$ \\
\hline & & \multirow{3}{*}{$\begin{array}{c}\text { Benefício } \\
\text { informativo alto }\end{array}$} & $\mathrm{BR}$ & $12.9 \%$ & \multirow{3}{*}{$35.9 \%$} \\
\hline & & & Ipiranga & $12.5 \%$ & \\
\hline & & & Texaco & $10.5 \%$ & \\
\hline & \multirow{2}{*}{$>3$ concorrentes } & $\begin{array}{c}\text { Benefício } \\
\text { informativo baixo }\end{array}$ & Gasolline & $67.2 \%$ & $67.2 \%$ \\
\hline & & $\begin{array}{c}\text { Benefício } \\
\text { informativo alto }\end{array}$ & $\begin{array}{r}\text { BR } \\
\text { Texaco }\end{array}$ & $\begin{array}{l}14.7 \% \\
18.1 \%\end{array}$ & $32.8 \%$ \\
\hline
\end{tabular}

Para efetuar a análise de preço, as análises foram feitas de acordo com algumas situações: o preço poderia estar acima ou abaixo do preço de mercado. A amostra estava dividida de acordo com a tabela 3. 
Tabela 3: Divisão da amostra quanto a preço e concorrência, autoria própria.

\begin{tabular}{c|c|c|c}
\hline \multirow{2}{*}{$\begin{array}{c}\text { Preço do } \\
\text { estabelecimento }\end{array}$} & $\leq 3$ concorrentes & Ocorrência & $30.55 \%$ \\
\cline { 2 - 4 } $\begin{array}{c}\text { menor que a média } \\
\text { do mercado }\end{array}$ & $>3$ concorrentes & Desvio padrão & 0.07 \\
\cline { 2 - 4 } & Ocorrência & $13.82 \%$ \\
\hline \multirow{2}{*}{$\begin{array}{c}\text { Preço do } \\
\text { estabelecimento } \\
\text { maior que a média } \\
\text { do mercado }\end{array}$} & $\leq 3$ concorrentes & Ocorrência & $38.69 \%$ \\
\cline { 2 - 4 } & $>3$ concorrentes & Desvio padrão & 0.04 \\
\cline { 2 - 4 } & Ocorrência & $16.94 \%$ \\
\hline
\end{tabular}

\subsection{Instrumento(s) de pesquisa}

Como instrumento de pesquisa utilizou-se dados secundários de observações em séries temporais. Esses dados estavam em relatórios do software Adaptive, que é um software de automação específico para revendedores de combustível. Os dados são alimentados no sistema automaticamente após cada abastecimento. Para que ocorra o abastecimento $o$ atendente deve liberar a bomba com um cartão, programar a bomba para a quantidade de litros ou valor a ser pago e o tipo de combustível a ser utilizado. Após esse procedimento, é informado o valor e a quantidade de litros ao cliente e, então, este efetua o pagamento.

\subsection{Procedimentos de coleta e de análise de dados}

No dia 27 de novembro de 2009, entrou-se em contato com uma administradora de revendedores de combustíveis possuidora de 16 estabelecimentos. Foram solicitados relatórios por abastecimento de cada uma das 16 empresas. Em 21 de dezembro de 2009, foram disponibilizados os relatórios com dados de 2 dias das 16 empresas, os quais somavam mais de 32 mil abastecimentos, sendo então necessário sumarizá-los. Para isso foram então solicitados dados diários. Esses dados estavam em bancos de dados do sistema e foram exportados para uma planilha de Excel 2007. Além desses dados foram verificados os serviços oferecidos, marca, localização do estabelecimento para se montar uma planilha. 
Foi feita uma análise de regressão linear múltipla e os pressupostos da normalidade das variáveis, multicoinearidades foram atendidas e o pressuposto da homocedaticidade foi um pouco violado a depender da análise específica. Foram feitas duas análises descritivas e inferenciais de análises de dados, nas quais foram computadas média e desvio padrão (estatística descritiva) e análise de regressão múltipla. Na primeira, as variáveis dependentes foram quantidade de clientes, receita vinda da venda de combustível e lucro vindo da venda de combustível dos postos em relação a todos os postos; na segunda as variáveis dependentes foram: quantidade de clientes, receita vinda da venda de combustível e lucro vindo da venda de combustível dos postos em relação a eles mesmos. Nas duas análises as variáveis independentes foram as mesmas, benefício utilitário, benefício informativo e preço. Para atender o pressuposto de linearidade a variável preço relativo médio total por posto foram transformadas em logaritmo. 


\section{RESULTADOS E DISCUSSÃO}

Foram feitas 6 análises de regressões múltiplas, 3 com as variáveis dependentes: quantidade de clientes, receita vinda da venda de combustível e lucro vindo da venda de combustível dos postos, em relação a todos os postos e $3 \mathrm{com}$ as variáveis dependentes (quantidade de clientes, receita vinda da venda de combustível e lucro vindo da venda de combustível dos postos em relação a eles mesmos). Em todas as 6, as variáveis independentes foram as mesmas, a saber: benefício informativo, benefício utilitário, log preço relativo médio total por posto. Inicialmente, serão apresentados os resultados das 3 regressões referentes à quantidade de clientes, receita vinda da venda de combustível e lucro vindo da venda de combustível dos postos em relação a todos os postos.

\subsection{Análise da variável dependente da quantidade de clientes em relação ao mercado}

Ao se analisar a variável dependente da quantidade de clientes (Tabela 4), observase que: na situação em que o preço do estabelecimento está menor que a média de mercado e com os concorrentes $\leq 3$, a variância explicada é de $37,7 \%$, todos os preditores apresentaram significância, o benefício informativo $(B=-0,25 ; p<0,01)$, o benefício utilitário $(B=0,51 ; p<0,01)$ e o preço $(B=2,15 ; p<0,01)$. Isso significa que a quantidade de clientes em relação a todos os postos pode ser explicada pelos três preditores quando se trata de uma situação, na qual existam até 3 concorrentes. Quanto menor o benefício informativo, maior a sua influência em aumentar a taxa de clientes em relação a todos os postos. Os resultados também demonstram que quanto maior o benefício utilitário, maior a sua influência no aumento da taxa de clientes em relação a todos os postos. Além disso, é possível observar que quanto maior a variação do preço, maior a influência em aumentar a taxa de clientes em relação a todos os postos. Esse aumento do preço pode estar relacionado à mudança diária de centavos e é importante observar que o preço do posto, mesmo com aumento, deve continuar abaixo do preço de mercado. 
$\mathrm{Na}$ situação em que o preço do estabelecimento está menor que a média de mercado e com os concorrentes $>3$, a variância explicada é de $10,1 \%$, todos os preditores apresentaram significância, o benefício informativo $(B=-0,22 ; p<0,01)$, o benefício utilitário $(B=0,09 ; p<0,01)$ e o preço $(B=3,46 ; p<0,01)$. Isso significa que a quantidade de clientes em relação a todos os postos pode ser explicada pelos três preditores quando se trata de uma situação, na qual existam mais de 3 concorrentes. Quanto menor o benefício informativo, maior a sua influência em aumentar a taxa de clientes em relação a todos os postos. Os resultados também demonstram que quanto maior o benefício utilitário, maior a sua influência no aumento da taxa de clientes em relação a todos os postos. Nesse caso a influência é menor do que quando existem mais de 3 concorrentes. Além disso, é possível observar que quanto maior a variação do preço, maior a influência em aumentar a taxa de clientes em relação a todos os postos nos casos em que o preço do estabelecimento está abaixo da média de mercado. Esse aumento do preço pode estar relacionado à mudança de centavos diária, até chegar próximo ao preço de mercado.

$\mathrm{Na}$ situação em que o preço do estabelecimento está maior que a média de mercado e com os concorrentes $\leq 3$, a variância explicada é de $31,5 \%$, apenas o preço não apresenta significância, o benefício informativo $(B=-0,27 ; p<0,01)$, o benefício utilitário $(B=0,48 ; p<0,01)$. Isso significa que a quantidade de clientes, em relação a todos os postos, pode ser explicada pelos benefícios informativo e utilitário, quando se trata de uma situação, na qual existam até 3 concorrentes. Quanto menor o benefício informativo, maior a sua influência em aumentar a taxa de clientes em relação a todos os postos. Os resultados também demonstram que quanto maior o benefício utilitário, maior a sua influência no aumento da taxa de clientes em relação a todos os postos. O preço não mostrou significância, não podendo então explicar o aumento ou decréscimo da quantidade de clientes nessa situação.

$\mathrm{Na}$ situação em que o preço do estabelecimento está maior que a média de mercado e com os concorrentes $>3$, a variância explicada é de $31,5 \%$, apenas o preço não apresenta significância, o benefício informativo $(B=-0,35 ; p<0,01)$, o benefício utilitário $(B=0,06 ; p<0,02)$. Isso significa que a quantidade de clientes em relação a todos os postos pode ser explicada pelos beneficios informativo e 
utilitário, quando se trata de uma situação, na qual existam mais de 3 concorrentes. Quanto menor o benefício informativo, maior a sua influência em aumentar a taxa de clientes em relação a todos os postos. Os resultados também demonstram que quanto maior o benefício utilitário, maior a sua influência no aumento da taxa de clientes em relação a todos os postos. Nesse caso a influência é menor do que quando existem até três concorrentes. O preço não mostrou significância, não podendo então explicar o aumento ou decréscimo da quantidade de clientes quando o preço do estabelecimento está acima do preço de mercado.

Essas situações podem ser observadas na tabela 4.

Tabela 4: Análise da variável dependente quantidade de clientes em relação ao mercado.

\begin{tabular}{|c|c|c|c|c|c|c|c|}
\hline Situação & Concorrência & $\mathrm{R}^{2}$ ajustado & $\begin{array}{c}\text { Variável } \\
\text { independente }\end{array}$ & B & Erro Padrão & $\beta$ & $\mathrm{P}$ \\
\hline \multirow{8}{*}{$\begin{array}{c}\text { Preço do } \\
\text { estabelecimento } \\
\text { menor que a } \\
\text { média de } \\
\text { mercado }\end{array}$} & \multirow{4}{*}{$\begin{array}{c}\leq 3 \\
\text { concorrentes }\end{array}$} & \multirow{4}{*}{.377} & Constante & -.52 & .02 & & .00 \\
\hline & & & $\begin{array}{l}\text { Benefício } \\
\text { informativo }\end{array}$ & -.25 & .01 & -.30 & .00 \\
\hline & & & $\begin{array}{l}\text { Benefício } \\
\text { utilitário }\end{array}$ & .51 & .01 & .63 & .00 \\
\hline & & & $\begin{array}{l}\log \text { preço } \\
\text { relativo médio } \\
\text { total por posto }\end{array}$ & 2.15 & .15 & .18 & .00 \\
\hline & \multirow{4}{*}{$\begin{array}{c}>3 \\
\text { concorrentes }\end{array}$} & \multirow{4}{*}{.101} & Constante & .14 & .03 & & .00 \\
\hline & & & $\begin{array}{l}\text { Benefício } \\
\text { informativo }\end{array}$ & -.22 & .03 & -.26 & .00 \\
\hline & & & $\begin{array}{l}\text { Benefício } \\
\text { utilitário }\end{array}$ & .09 & .02 & .11 & .00 \\
\hline & & & $\begin{array}{l}\qquad \log \text { preço } \\
\text { relativo médio } \\
\text { total por posto }\end{array}$ & 3.46 & .30 & .26 & .00 \\
\hline \multirow{8}{*}{$\begin{array}{c}\text { Preço do } \\
\text { estabelecimento } \\
\text { maior que a } \\
\text { média de } \\
\text { mercado }\end{array}$} & \multirow{4}{*}{$\begin{array}{c}\leq 3 \\
\text { concorrentes }\end{array}$} & \multirow{4}{*}{.315} & Constante & -.48 & .02 & & .00 \\
\hline & & & $\begin{array}{c}\text { Benefício } \\
\text { informativo }\end{array}$ & -.27 & .01 & -.31 & .00 \\
\hline & & & $\begin{array}{l}\text { Benefício } \\
\text { utilitário }\end{array}$ & .48 & .01 & .53 & .00 \\
\hline & & & $\begin{array}{l}\qquad \log \text { preço } \\
\text { relativo médio } \\
\text { total por posto }\end{array}$ & -.22 & .27 & -.01 & .42 \\
\hline & \multirow{4}{*}{$\begin{array}{c}>3 \\
\text { concorrentes }\end{array}$} & \multirow{4}{*}{.103} & Constante & .23 & .04 & & .00 \\
\hline & & & $\begin{array}{c}\text { Benefício } \\
\text { informativo }\end{array}$ & -.35 & .03 & -.36 & .00 \\
\hline & & & $\begin{array}{l}\text { Benefício } \\
\text { utilitário }\end{array}$ & .06 & .02 & .07 & .01 \\
\hline & & & $\begin{array}{l}\log \text { preço } \\
\text { relativo médio } \\
\text { total por posto }\end{array}$ & .31 & .55 & .01 & .58 \\
\hline
\end{tabular}


Observa-se que em todas as situações desse cenário o benefício informativo tem uma relação negativa com a quantidade de clientes, ou seja, o aumento desse benefício pode ser responsável por uma diminuição na quantidade de clientes nessas situações. No estudo de Oliveira-Castro, Foxall e Schrezenmaier (2005), no qual foram pesquisados produtos: a influência de preço, benefício utilitário e informativo na compra de 9 alimentícios, o benefício informativo apresentou a característica inversamente proporcional em 8 das 9 categorias. Já em relação ao benefício utilitário, a relação foi positiva, mostrando que o aumento do benefício utilitário tem uma influência no aumento da quantidade de clientes de um posto em relação aos demais, ao contrário do que foi observado no estudo de Oliveira-Castro, Foxall e Schrezenmaier (2005) com 9 categorias de comida. Nesse estudo, em 8 das 9 categorias pesquisadas a relação foi negativa. Já o preço apenas tem influência quando o preço do estabelecimento se encontra abaixo do preço de mercado. O aumento deste tem influência no aumento da quantidade de clientes. Isso pode ser explicado, porque o preço continua abaixo do preço de mercado, contudo, a mudança de centavos faz com que este esteja maior, ou seja, quanto mais alto, mais clientes desde que esteja abaixo do preço dos outros postos. $\mathrm{Na}$ pesquisa de Oliveira-Castro, Foxall e Schrezenmaier (2005), a relação se mostra negativa para todas as categorias alimentícias pesquisadas, porém não são controlados a quantidade de concorrentes, preço e relação com o mercado. $O$ aumento do preço não influência a quantidade de clientes quando o preço do estabelecimento está acima da média de mercado. Para os três preditores os gráficos de resíduos mostraram-se bastante aleatórios. O estudo de Oliveira-Castro, Foxall e Schrezenmaier (2005) foi utilizado como base, por não se encontrar produtos com a categoria semelhante da pesquisada nesse estudo.

\subsection{Análise da variável dependente receita proveniente da venda de combustível em relação ao mercado}

$\mathrm{Na}$ Tabela 5, demonstra-se os resultados no qual estão sendo observadas as relações de preço, beneficio utilitário e informativo dos postos em relação a todos os 
postos ao se estudar a variável dependente receita vinda da venda de combustível, observa-se que:

Na situação em que o preço do estabelecimento é menor que a média de mercado e com os concorrentes $\leq 3$, a variância explicada é de $23,3 \%$, todos os preditores apresentaram significância, o benefício informativo $(B=-0,12 ; p<0,01)$, o benefício utilitário $(B=0,38 ; p<0,01)$ e o preço $(B=1,73 ; p<0,01)$. Isso significa que a receita proveniente de venda de combustíveis dos postos em relação a todos os postos pode ser explicada pelos três preditores. $O$ benefício informativo apresenta uma relação negativa, ou seja, o seu aumento tem influência no decréscimo da receita vinda da venda de combustível, já o benefício utilitário e o preço apresentam numa relação positiva, pois o seu aumento influência o aumento da receita vinda da venda de combustíveis.

Na situação em que o preço do estabelecimento é menor que a média de mercado e com os concorrentes > 3 , a variância explicada é de $14,1 \%$, todos os preditores apresentaram significância, o benefício informativo ( $B=0,20 ; p<0,01)$, o benefício utilitário $(B=0,05 ; p<0,04)$ e o preço $(B=3,39 ; p<0,01)$. Isso significa que 0 aumento da receita pode ser explicada pelo aumento dos três preditores, quando se trata de uma situação, na qual existam mais de 3 concorrentes. Nesse caso a relação com os três preditores é positiva, ou seja, um aumento no beneficio informativo influência um aumento da receita; um aumento no benefício utilitário influência um aumento da receita, assim como o aumento do preço.

Na situação em que o preço do estabelecimento é maior que a média de mercado e com os concorrentes $\leq 3$, a variância explicada é de $20 \%$, todos os preditores apresentaram significância, o benefício informativo $(B=-0,07 ; p<0,01)$, o benefício utilitário $(B=0,34 ; p<0,01)$ e o preço $(B=-1,238 ; p<0,01)$. Isso significa que a receita pode ser explicada pelos três preditores, quando se trata de uma situação, na qual existam até 3 concorrentes. Nesse caso, diferentemente de quando o preço está menor que a média de mercado, o preço tem uma influência negativa na receita e o aumento do preço influência o decréscimo da receita proveniente da venda de combustíveis. Os resultados também demonstram que quanto maior o benefício informativo, maior a influência no decréscimo da receita vinda da venda de combustíveis. Já o aumento benefício utilitário tem influência no aumento da receita 
vinda da venda de combustíveis em um ambiente em que o preço do estabelecimento está maior que a média de mercado.

Na situação em que o preço do estabelecimento é maior que a média de mercado e com concorrentes $>3$, nenhum dos preditores tem significância, ou seja, o benefício informativo, o benefício utilitário e o preço não explicam o aumento ou a diminuição da receita, quando o preço do estabelecimento está acima do preço de mercado e este possui mais de 3 concorrentes.

Essas situações podem ser observadas pela tabela 5:

Tabela 5: Análise da variável dependente receita em relação ao mercado.

\begin{tabular}{|c|c|c|c|c|c|c|c|}
\hline Situação & Concorrência & $\mathrm{R}^{2}$ ajustado & $\begin{array}{c}\text { Variável } \\
\text { independente }\end{array}$ & B & Erro Padrão & $\beta$ & $\mathrm{P}$ \\
\hline \multirow{8}{*}{$\begin{array}{l}\text { Preço do } \\
\text { estabelecimento } \\
\text { menor que a } \\
\text { média de } \\
\text { mercado }\end{array}$} & \multirow{4}{*}{$\begin{array}{c}\leq 3 \\
\text { concorrentes }\end{array}$} & \multirow{4}{*}{.243} & Constante & -.54 & .02 & & .00 \\
\hline & & & $\begin{array}{l}\text { Benefício } \\
\text { informativo }\end{array}$ & -.12 & .01 & -.16 & .00 \\
\hline & & & Benefício utilitário & .38 & .01 & .51 & .00 \\
\hline & & & $\begin{array}{l}\log \text { preço relativo } \\
\text { médio total por posto }\end{array}$ & 1.73 & .16 & .15 & .00 \\
\hline & \multirow{4}{*}{$\begin{array}{c}>3 \\
\text { concorrentes }\end{array}$} & \multirow{4}{*}{.141} & Constante & -.27 & .03 & & .00 \\
\hline & & & $\begin{array}{l}\text { Benefício } \\
\text { informativo }\end{array}$ & .20 & .03 & .23 & .00 \\
\hline & & & Benefício utilitário & .05 & .02 & .06 & .03 \\
\hline & & & $\begin{array}{l}\log \text { preço relativo } \\
\text { médio total por posto }\end{array}$ & 3.39 & .31 & .24 & .00 \\
\hline \multirow{8}{*}{$\begin{array}{l}\text { Preço do } \\
\text { estabelecimento } \\
\text { maior que a } \\
\text { média de } \\
\text { mercado }\end{array}$} & \multirow{4}{*}{$\begin{array}{c}\leq 3 \\
\text { concorrentes }\end{array}$} & \multirow{4}{*}{.200} & Constante & -.51 & .02 & & .00 \\
\hline & & & $\begin{array}{l}\text { Benefício } \\
\text { informativo }\end{array}$ & -.07 & .01 & -.09 & .00 \\
\hline & & & Benefício utilitário & .34 & .01 & .45 & .00 \\
\hline & & & $\begin{array}{l}\log \text { preço relativo } \\
\text { médio total por posto }\end{array}$ & -1.24 & .25 & -.06 & .00 \\
\hline & \multirow{4}{*}{$\begin{array}{c}>3 \\
\text { concorrentes }\end{array}$} & \multirow{4}{*}{.001} & Constante & -.11 & .04 & & .00 \\
\hline & & & $\begin{array}{l}\text { Benefício } \\
\text { informativo }\end{array}$ & .02 & .03 & .02 & .43 \\
\hline & & & Benefício utilitário & .02 & .03 & .02 & .51 \\
\hline & & & $\begin{array}{l}\log \text { preço relativo } \\
\text { médio total por posto }\end{array}$ & .85 & .56 & .03 & .13 \\
\hline
\end{tabular}


Nesses resultados foram observados: a relação de preço, benefício informativo e utilitário dos postos em relação a todos os postos na receita vinda da venda de combustíveis. $O$ benefício informativo apenas representou uma relação positiva na situação em que o preço está menor que a média de mercado, ou seja, esta é a única situação, na qual um aumento do benefício informativo influencia o aumento da receita proveniente da venda de combustíveis. Nas outras situações, exceto a que não se mostrou significativa, o aumento do benefício informativo influencia o decréscimo da receita. Já o aumento do benefício utilitário, em todos os casos que se mostrou significativo, influencia o aumento da receita vinda da venda de combustíveis. No estudo de Oliveira-Castro, Foxall, James, Pohl, Dias e Chang (2008) no qual eles fizeram uma pesquisa para descobrir o brand equity baseado nas percepções do consumidor, eles utilizaram perguntas relacionadas ao benefício utilitário e informativo dos produtos alimentícios pesquisados no Reino Unido, eles observaram, que o aumento do brand equity baseado nas percepções do consumidor aumentava a receita da marca, esse estudo, porém, não dividiu qual dos benefícios acarretava no aumento do brand equity baseado nas percepções do consumidor e consequentemente da receita. Nesse estudo o preço se mostrou significativo em apenas 2 casos.

Os resultados também mostraram que apenas na situação em que o preço do estabelecimento estava acima do preço de mercado, o aumento do preço influência o decréscimo da receita, porque nas outras situações em que se mostraram significativas, o aumento do preço influência o aumento da receita proveniente da venda de combustível. No estudo sobre comportamento de consumo em compras pela internet, Boyd (2004) afirma que devido à competitividade, as empresas devem se preocupar mais com o preço para maximizar a receita. Isso pode ser percebido nesse estudo, já que o preditor que mais influência a receita é preço. Para os três preditores os gráficos de resíduos mostraram-se bastante aleatórios. 


\subsection{Análise da variável dependente lucro proveniente da venda de combustível em relação ao mercado}

Na tabela 6 é possível observar as relações de benefício utilitário, benefício informativo e preço em relação ao lucro proveniente da venda de combustíveis dos postos em relação a todos os outros postos, observa-se que:

$\mathrm{Na}$ situação em que o preço do estabelecimento está menor que a média de mercado e com os concorrentes $\leq 3$, a variância explicada é de $45,2 \%$, todos os preditores apresentaram significância, o benefício informativo $(B=-0,33 ; p<0,01)$, o benefício utilitário $(B=0,32 ; p<0,01)$ e o preço $(B=9,30 ; p<0,01)$. Isso significa que o lucro proveniente da venda de combustíveis pode ser explicado pelos três preditores. Quanto menor o benefício informativo, maior a sua influência em aumentar o lucro vindo da venda de combustíveis. Os resultados também demonstram que quanto maior o benefício utilitário, maior a sua influência no aumento do lucro vindo da venda de combustíveis. Além disso, é possível observar que quanto maior o preço, maior a influência no aumento do lucro vindo da venda de combustíveis.

$\mathrm{Na}$ situação em que o preço do estabelecimento está menor que a média de mercado e com os concorrentes > 3, a variância explicada é de $42,6 \%$, todos os preditores apresentaram significância, o benefício informativo $(B=-0,063 ; p<0,03)$, o benefício utilitário $(B=0,13 ; p<0,01)$ e o preço $(B=11,54 ; p<0,01)$. Isso significa que o lucro pode ser explicado pelos três preditores, de forma que quanto menor o benefício informativo, maior a influência no aumento do lucro vindo da venda de combustível. Os resultados também mostraram que a relação do benefício utilitário e preço são positivas, ou seja, o aumento no preço e/ou no benefício utilitário influenciam no aumento da receita proveniente da venda de combustível.

$\mathrm{Na}$ situação em que o preço do estabelecimento está maior que a média de mercado e com os concorrentes $\leq 3$, a variância explicada é de $24,7 \%$, todos os preditores apresentaram significância, o benefício informativo $(B=-0,30 ; p<0,01)$, o benefício utilitário $(B=0,32 ; p<0,01)$ e o preço $(B=-1,26, p<0,01)$. Isso significa que o aumento ou decréscimo do lucro proveniente da venda de combustíveis pode ser explicado pelos três preditores. De acordo com os resultados a diminuição no benefício utilitário influencia o aumento nos lucros provenientes da venda de 
combustível. Já em relação ao benefício utilitário é possível concluir que um aumento nele influência um aumento nos lucros vindos da venda de combustível. Os resultados também mostraram que existe uma relação negativa entre o lucro vindo da venda de combustíveis e o preço, ou seja, um aumento no preço influência um decréscimo no lucro.

$\mathrm{Na}$ situação em que o preço do estabelecimento está maior que a média de mercado e com os concorrentes > 3, a variância explicada é de 5,4\%, apenas o preço não apresentou significância, o benefício informativo $(B=-0,25 ; p<0,01)$, 0 benefício utilitário $(B=0,05 ; p<0,04)$. Isso significa que o lucro pode ser explicado pelo benefício informativo e utilitário. Neste caso, os resultados mostram que quanto menor o benefício informativo, maior a influência nos lucros vindos da venda de combustível. Em relação ao benefício utilitário, a relação é positiva, ou seja, o seu aumento influencia um aumento dos lucros vindos da venda de combustível.

Essas relações podem ser observadas na tabela 6:

Tabela 6: Análise da variável dependente lucro em relação ao mercado.

\begin{tabular}{|c|c|c|c|c|c|c|c|}
\hline Situação & Concorrência & $\begin{array}{c}\mathrm{R}^{2} \\
\text { ajustado }\end{array}$ & Variável independente & $\mathrm{B}$ & $\begin{array}{c}\text { Erro } \\
\text { Padrão }\end{array}$ & $\beta$ & $\mathrm{P}$ \\
\hline \multirow{8}{*}{$\begin{array}{c}\text { Preço do } \\
\text { estabelecimento } \\
\text { menor que a média } \\
\text { de mercado }\end{array}$} & \multirow{4}{*}{$\begin{array}{c}\leq 3 \\
\text { concorrentes }\end{array}$} & \multirow{4}{*}{.452} & Constante & -.08 & .02 & & .01 \\
\hline & & & Benefício informativo & -.33 & .01 & -.30 & .00 \\
\hline & & & Benefício utilitário & .32 & .01 & .31 & .00 \\
\hline & & & $\begin{array}{l}\text { log preço relativo } \\
\text { médio total por posto }\end{array}$ & 9.30 & .19 & .58 & .00 \\
\hline & \multirow{4}{*}{$\begin{array}{c}>3 \\
\text { concorrentes }\end{array}$} & \multirow{4}{*}{.426} & Constante & .06 & .03 & & .09 \\
\hline & & & Benefício informativo & -.06 & .03 & -.06 & .02 \\
\hline & & & Benefício utilitário & .13 & .03 & .13 & .00 \\
\hline & & & $\begin{array}{l}\text { log preço relativo } \\
\text { médio total por posto }\end{array}$ & 11.54 & .32 & .64 & .00 \\
\hline \multirow{8}{*}{$\begin{array}{l}\text { Preço do } \\
\text { estabelecimento } \\
\text { maior que a média } \\
\text { de mercado }\end{array}$} & \multirow{4}{*}{$\begin{array}{c}\leq 3 \\
\text { concorrentes }\end{array}$} & \multirow{4}{*}{.247} & Constante & -.12 & .02 & & .00 \\
\hline & & & Benefício informativo & -.30 & .01 & -.38 & .00 \\
\hline & & & Benefício utilitário & .32 & .01 & .40 & .00 \\
\hline & & & $\begin{array}{l}\text { log preço relativo } \\
\text { médio total por posto }\end{array}$ & -1.26 & .25 & -.06 & .00 \\
\hline & \multirow{4}{*}{$\begin{array}{c}>3 \\
\text { concorrentes }\end{array}$} & \multirow{4}{*}{.054} & Constante & .24 & .04 & & .00 \\
\hline & & & Benefício informativo & -.25 & .03 & -.26 & .00 \\
\hline & & & Benefício utilitário & .05 & .02 & .06 & .03 \\
\hline & & & $\begin{array}{l}\text { log preço relativo } \\
\text { médio total por posto }\end{array}$ & .85 & .56 & .03 & .13 \\
\hline
\end{tabular}


Nesta análise foram observados: a influência do preço, os benefícios informativo e utilitário dos postos em relação a todos os postos no lucro vindo da venda de combustíveis. Os resultados mostraram que quanto menor o benefício informativo, maior a influência no aumento dos lucros oriundos da venda de combustíveis, sendo que a maior influência é no caso em que existem acima de 3 concorrentes e que o posto está com o preço menor que a média de mercado. Isso pode acontecer devido ao fato que os distribuidores vendem seus produtos mais caros aos revendedores que carregam a sua bandeira, devido ao contrato de exclusividade, como dito por Pinto e Silva (2004). No estudo apresentado as marcas com maior benefício informativo, possuem contrato de exclusividade com a distribuidora, ao contrario da marca com menor benefício informativo, que pode comprar combustível de qualquer distribuidora. Já o benefício utilitário, em todos os casos, apresentou uma relação positiva com o lucro, ou seja, seu aumento influencia no aumento dos lucros provenientes da venda de combustível. Como afirmam Hauser e Shugan (1983), o potencial lucrativo diminui com o aumento da competição. No estudo foi possível perceber que quanto maior a competição, menor o efeito dos investimentos em benefício informativo e utilitário, pois estes passam a influenciar menos quanto maior a competição. Os resultados também mostraram que considerando os casos em que se mostraram significativos, exceto na situação em que existem até 3 concorrentes e o estabelecimento está com o preço acima da média de mercado, a diminuição do preço influencia o aumento dos lucros vindos da venda de combustível. Nos outros casos o aumento do preço influencia um aumento desse lucro. Esse resultado vai ao encontro do que Levitt (1983) prevê, ou seja, que com o aumento da competição o que mais importa no mercado é o preço. Para os três preditores os gráficos de resíduos mostraram-se bastante aleatórios.

As outras análises efetuadas foram as regressões múltiplas com as variáveis dependentes: quantidade de clientes, receita vinda da venda de combustível e lucro vindo da venda de combustível dos postos em relação a eles mesmos. As variáveis independentes foram as mesmas: benefício informativo, benefício utilitário, log preço relativo médio total por posto. 


\subsection{Análise da variável dependente quantidade de clientes em relação próprio revendedor}

Ao se analisar a quantidade de clientes de um posto em relação a ele mesmo, na situação em que o preço do estabelecimento está que é menor que a média de mercado e com os concorrentes $\leq 3$, (Tabela 7) a variância explicada é de $8,4 \%$, apenas o benefício informativo não apresentou significância, o benefício utilitário ( $B$ $=0,02 ; p<0,04)$ e o preço $(B=2,26 ; p<0,01)$ apresentaram significância. Isso significa que a quantidade de clientes em relação ao próprio posto pode ser explicada pelo benefício utilitário e pelo preço. Os estudos apontam para o aspecto de que quanto maior o benefício utilitário, maior a influência no aumento da quantidade de clientes em relação ao próprio estabelecimento. O preço também apresenta uma relação positiva com a quantidade de clientes, ou seja, quanto maior o preço, maior a influência no aumento da quantidade de clientes. Esse aumento do preço pode estar relacionado à mudança de centavos diária e é importante observar que o preço do posto, mesmo com o aumento do preço, deve continuar abaixo do preço de mercado.

$\mathrm{Na}$ situação em que o preço do estabelecimento está menor que a média de mercado e com os concorrentes > 3, a variância explicada é de 9,6\%, apenas o preço apresentou significância $(B=3,10 ; p<0,01)$. Isso significa que a quantidade de clientes em relação ao próprio posto pode ser explicada pelo preço, ou seja, quanto maior o preço, maior a influência no aumento da quantidade de clientes. Lembrando que pode haver uma alteração diária nos centavos do combustível e que este deve permanecer abaixo da média de mercado.

$\mathrm{Na}$ situação em que o preço do estabelecimento está maior que a média de mercado e com os concorrentes $\leq 3$ a variância explicada é de 0,5\%, apenas o preço apresentou significância $(B=-1,07 ; p<0,01)$. Isso significa o preço apresenta uma influência na quantidade de clientes de forma inversamente proporcional, ou seja, quanto menor o preço, maior a quantidade de clientes do posto em relação a ele mesmo.

$\mathrm{Na}$ situação em que o preço do estabelecimento está maior que a média de mercado e com os concorrentes > 3, a variância explicada é de $2,8 \%$, todos os preditores apresentaram significância, o benefício informativo $(B=-0,06 ; p<0,01)$, 
benefício utilitário $(B=-0,05 ; p<0,01)$ e o preço $(B=-1,77 ; p<0,01)$. Isso significa que quantidade de clientes em relação ao próprio posto pode ser explicada pelos três predidores. Os resultados mostram que quanto menor o nível de benefício informativo, maior a sua influência na quantidade de clientes de um revendedor de combustível em relação a ele mesmo. Os estudos apontam que quanto menor o benefício utilitário, maior a influência no aumento da quantidade de clientes em relação ao próprio estabelecimento. O preço também apresenta uma relação inversamente proporcional com a quantidade de clientes, ou seja, quanto menor o preço maior a influência no aumento da quantidade de clientes.

Conforme pode ser observado na tabela 7.

Tabela 7: Análise da variável dependente quantidade de clientes em relação ao próprio posto.

\begin{tabular}{|c|c|c|c|c|c|c|c|}
\hline Situação & Concorrência & $\begin{array}{c}\mathrm{R}^{2} \\
\text { ajustado }\end{array}$ & Variável independente & B & $\begin{array}{c}\text { Erro } \\
\text { Padrão }\end{array}$ & $\beta$ & $\mathrm{P}$ \\
\hline \multirow{8}{*}{$\begin{array}{c}\text { Preço do } \\
\text { estabelecimento } \\
\text { menor que a } \\
\text { média de } \\
\text { mercado }\end{array}$} & \multirow{4}{*}{$\begin{array}{c}\leq 3 \\
\text { concorrentes }\end{array}$} & \multirow{4}{*}{.084} & Constante & -.01 & .02 & & .65 \\
\hline & & & Benefício informativo & -.01 & .01 & -.02 & .13 \\
\hline & & & Benefício utilitário & .02 & .01 & .05 & .00 \\
\hline & & & $\begin{array}{l}\log \text { preço relativo } \\
\text { médio total por posto }\end{array}$ & 2.26 & .12 & .29 & .00 \\
\hline & \multirow{4}{*}{$\begin{array}{c}>3 \\
\text { concorrentes }\end{array}$} & \multirow{4}{*}{.096} & Constante & .03 & .02 & & .15 \\
\hline & & & Benefício informativo & -.02 & .02 & -.03 & .34 \\
\hline & & & Benefício utilitário & .02 & .02 & .03 & .38 \\
\hline & & & $\begin{array}{l}\log \text { preço relativo } \\
\text { médio total por posto }\end{array}$ & 3.10 & .23 & .31 & .00 \\
\hline \multirow{8}{*}{$\begin{array}{c}\text { Preço do } \\
\text { estabelecimento } \\
\text { maior que a } \\
\text { média de } \\
\text { mercado }\end{array}$} & \multirow{4}{*}{$\begin{array}{c}\leq 3 \\
\text { concorrentes }\end{array}$} & \multirow{4}{*}{.005} & Constante & .04 & .02 & & .02 \\
\hline & & & Benefício informativo & -.01 & .01 & -.02 & .13 \\
\hline & & & Benefício utilitário & -.01 & .01 & -.01 & .31 \\
\hline & & & $\begin{array}{l}\text { log preço relativo } \\
\text { médio total por posto }\end{array}$ & -1.07 & .20 & -.08 & .00 \\
\hline & \multirow{4}{*}{$\begin{array}{c}>3 \\
\text { concorrentes }\end{array}$} & \multirow{4}{*}{.028} & Constante & .17 & .03 & & .00 \\
\hline & & & Benefício informativo & -.06 & .02 & -.09 & .00 \\
\hline & & & Benefício utilitário & -.05 & .02 & -.08 & .00 \\
\hline & & & $\begin{array}{l}\text { log preço relativo } \\
\text { médio total por posto }\end{array}$ & -1.77 & .41 & -.09 & .00 \\
\hline
\end{tabular}


Nesta análise foram observados: a influência do preço, os benefícios informativo e utilitário na quantidade de clientes dos postos em relação ao próprio posto. 0 benefício informativo apenas se mostrou significativo no caso em que o posto está com o preço acima da média de mercado e possui acima de três concorrentes, nesse caso quanto menor o benefício informativo, maior a sua influência na quantidade de clientes. O que esta de acordo com o estudo de Oliveira-Castro, Foxall e Schrezenmaier (2005) no qual eles afirmam que os consumidores tendem a comprar em menor quantidade produtos com maior benefício informativo. O preço se mostrou significativo em todos os casos. Nas situações em que o preço do estabelecimento está menor que a média da concorrência, a relação foi positiva, ou seja, quanto maior o preço, maior a influência na quantidade de clientes em relação ao próprio posto; já nos casos em que o preço do posto está acima do preço de mercado, a influência é inversamente proporcional, ou seja, quanto menor o preço, maior a influência no aumento da quantidade de clientes em relação ao próprio posto. O que corrobora com os resultados de Oliveira-Castro, Foxall e Schrezenmaier (2005) que afirmam que os consumidores tendem a comprar maior quantidade quando o preço do produto está menor que a média de mercado, na análise feita na situação que o preço está menor que a média de mercado a relação foi positiva, porém o preço continua abaixo da média de mercado como afirmado por Oliveira-Castro, Foxall e Schrezenmaier (2005), já quando o preço está acima da média de mercado, deve ocorrer a diminuição do preço para aumentar a quantidade de clientes. Os resultados também mostraram que o benefício utilitário se mostrou significativo em dois casos; caso o estabelecimento possua até três concorrentes e esteja com o preço abaixo do preço de mercado, quanto maior o benefício utilitário, maior a influência no aumento da quantidade de clientes em relação ao próprio estabelecimento; caso o estabelecimento esteja com o preço acima do preço de mercado e tenha acima de três concorrentes, quanto menor o benefício utilitário, maior a sua influência na quantidade de clientes em relação ao próprio posto. No estudo de Oliveira-Castro, Foxall e Schrezenmaier (2005) os clientes compram menos do produto com maior beneficio utilitário, essa relação foi possível de verificar quando o preço está acima da média de mercado, porém nos resultados quando o preço está abaixo da média de mercado ele tende a maximizar os benefícios. 
Isso se assemelha ao estudo de Walters (1991), em uma rede de supermercados, no qual observa-se que com a promoção de preço dos produtos houve uma ascensão nas suas vendas. No estudo realizado, isso só influencia, quando o preço está acima do preço de mercado. No caso dele está abaixo do preço de mercado, a variação positiva de preço influencia o aumento da quantidade de clientes, devido às estratégias de precificação.

\subsection{Análise da variável dependente receita proveniente da venda de combustível em relação próprio revendedor}

$\mathrm{Na}$ Tabela 8, ao se analisar as relações de benefício informativo, benefício utilitário e preço com a receita proveniente da venda de combustíveis de um posto em relação a ele mesmo, na situação em que o preço do estabelecimento está que é menor que a média de mercado e com os concorrentes $\leq 3$, a variância explicada é de $3,8 \%$, os três preditores apresentaram significância, o benefício informativo $(B=$ $0,05 ; p<0,01)$, o benefício utilitário $(B=0,03 ; p<0,02)$ e o preço $(B=1,79 ; p<$ $0,01)$. Isso significa que em relação ao benefício informativo, quanto menor este for, maior a influência na receita em relação ao próprio estabelecimento. Os resultados também mostram que quanto maior o benefício utilitário, maior a influência no aumento da receita em relação ao próprio estabelecimento. Quanto ao preço, a relação é positiva e quanto maior for o preço, maior a influência na receita em relação ao próprio estabelecimento.

$\mathrm{Na}$ situação em que o preço do estabelecimento está menor que a média de mercado e com os concorrentes $>3$, a variância explicada é de $6,5 \%$, apenas 0 preço apresentou significância $(B=2,89 ; p<0,01)$. Isso significa que quanto maior $o$ preço, maior será a influência na receita vinda da venda de combustíveis em relação ao próprio posto.

$\mathrm{Na}$ situação em que o preço do estabelecimento está maior que a média de mercado e com os concorrentes $\leq 3$, a variância explicada é de $0,2 \%$, apenas o preço apresentou significância $(B=-0,77 ; p<0,01)$. Isso significa que quanto menor for o preço, maior será a influência na receita vinda da venda de combustíveis em relação próprio posto. 
$\mathrm{Na}$ situação em que o preço do estabelecimento está maior que a média de mercado e com os concorrentes > 3, a variância explicada é de $2,9 \%$, apenas o preço não apresentou significância, o benefício informativo $(B=-0,1 ; p<0,01)$ e o benefício utilitário $(B=-0,05 ; p<0,03)$. Isso significa que quanto menor o benefício utilitário, maior a influência na receita vinda da venda de combustíveis em relação ao próprio posto. Os resultados também mostram que o benefício utilitário também apresenta uma relação inversamente proporcional, ou seja, quanto menor o benefício utilitário, maior a influência na receita.

Tabela 8: Análise da variável dependente receita em relação ao próprio revendedor.

\begin{tabular}{|c|c|c|c|c|c|c|c|}
\hline Situação & Concorrência & $\begin{array}{c}\mathrm{R}^{2} \\
\text { ajustado }\end{array}$ & Variável independente & $\mathrm{B}$ & $\begin{array}{c}\text { Erro } \\
\text { Padrão }\end{array}$ & $\beta$ & $\mathrm{P}$ \\
\hline \multirow{8}{*}{$\begin{array}{c}\text { Preço do } \\
\text { estabelecimento } \\
\text { menor que a } \\
\text { média de } \\
\text { mercado }\end{array}$} & \multirow{4}{*}{$\begin{array}{c}\leq 3 \\
\text { concorrentes }\end{array}$} & \multirow{4}{*}{.038} & Constante & .00 & .02 & & .844 \\
\hline & & & Benefício informativo & -.05 & .01 & -.072 & .00 \\
\hline & & & Benefício utilitário & .03 & .01 & .041 & .01 \\
\hline & & & $\begin{array}{l}\log \text { preço relativo } \\
\text { médio total por posto }\end{array}$ & 1.79 & .15 & .187 & .00 \\
\hline & \multirow{4}{*}{$\begin{array}{c}>3 \\
\text { concorrentes }\end{array}$} & \multirow{4}{*}{.065} & Constante & .00 & .03 & & .98 \\
\hline & & & Benefício informativo & -.01 & .02 & -.014 & .65 \\
\hline & & & Benefício utilitário & .02 & .02 & .032 & .30 \\
\hline & & & $\begin{array}{l}\text { log preço relativo } \\
\text { médio total por posto }\end{array}$ & 2.89 & .26 & .257 & .00 \\
\hline \multirow{8}{*}{$\begin{array}{c}\text { Preço do } \\
\text { estabelecimento } \\
\text { maior que a } \\
\text { média de } \\
\text { mercado }\end{array}$} & \multirow{4}{*}{$\begin{array}{c}\leq 3 \\
\text { concorrentes }\end{array}$} & \multirow{4}{*}{.002} & Constante & -.02 & .02 & & .40 \\
\hline & & & Benefício informativo & .00 & .01 & -.002 & .89 \\
\hline & & & Benefício utilitário & .01 & .01 & .013 & .36 \\
\hline & & & $\begin{array}{l}\log \text { preço relativo } \\
\text { médio total por posto }\end{array}$ & -.77 & .24 & -.047 & .00 \\
\hline & \multirow{4}{*}{$\begin{array}{c}>3 \\
\text { concorrentes }\end{array}$} & \multirow{4}{*}{.029} & Constante & .17 & .03 & & .00 \\
\hline & & & Benefício informativo & -.10 & .02 & -.126 & .00 \\
\hline & & & Benefício utilitário & -.05 & .02 & -.064 & .02 \\
\hline & & & $\begin{array}{l}\text { log preço relativo } \\
\text { médio total por posto }\end{array}$ & -.73 & .45 & -.035 & .10 \\
\hline
\end{tabular}


Nesta análise foram observados: a influência do preço, o benefício informativo e utilitário na receita proveniente da venda de combustíveis dos postos em relação ao próprio posto. O benefício informativo mostrou-se significativo no caso do posto que está com o preço abaixo da média de mercado e possui até três concorrentes. Nesse caso quanto menor o benefício informativo, maior a sua influência na receita proveniente da venda de combustível. O outro caso em que se mostrou significativo foi o caso do posto que está com o preço acima da média do preço de mercado. Também nesse caso, quanto menor o benefício informático, maior a influência na receita proveniente da venda de combustíveis relativa ao próprio posto. Os resultados também mostram que o benefício utilitário apresenta significância quando o posto possui até três concorrentes e está com o preço abaixo do preço de mercado. Neste caso quanto maior o benefício utilitário, maior a receita, porém quando o posto está com o preço acima do preço de mercado e possui mais de três concorrentes, a relação é inversa, então, quanto menor o benefício utilitário, maior a influência no aumento da receita proveniente da venda de combustíveis. O preço mostrou-se significativo em três casos, quando o posto está com o preço abaixo do preço de mercado, independente da quantidade de concorrentes a relação é positiva e quanto maior a quantidade e o preço, maior a influência na receita vinda da venda de combustível em relação ao próprio posto. Já no caso em que o posto possui até três concorrentes e está com o preço acima do preço de mercado, a relação com a receita é inversamente proporcional, ou seja, quanto menor o preço, maior a influência no aumento da receita. No estudo de Oliveira-Castro, Foxall, James, Pohl, Dias e Chang (2008) no qual eles fizeram uma pesquisa para descobrir o brand equity baseado nas percepções do consumidor que esta relacionado aos benefícios utilitários e informativos dos produtos, no Brasil, em 5 dos 11 produtos o aumento do market share estava relacionado com o aumento do brand equity baseado nas percepções do consumidor e não no preço, eles também afirmam que o aumento desse market share estava associado ao aumento da receita. Ao contrario do que aconteceu no estudo apresentado, no caso dos revendedores de combustível o mais influente foi o preço.

Já no estudo de gestão de receita de companhias aéreas, Vinod (2010) afirma que para essa boa gestão é necessário que a companhia tenha uma gestão efetiva das tarifas, ou seja, assim como foi visto no trabalho, o mais influente para aumentar a receita em relação ao próprio posto é a boa gestão dos preços. 


\subsection{Análise da variável dependente lucro proveniente da venda de combustível em relação próprio revendedor}

Ao se analisar o lucro proveniente da venda de combustíveis de um posto em relação a ele mesmo (Tabela 8 ), na situação em que o preço do estabelecimento está menor que a média de mercado e com os concorrentes $\leq 3$, a variância explicada é de $43,5 \%$, apenas o benefício informativo não apresentou significância, o benefício utilitário $(B=-0,03 ; p<0,01)$ e o preço $(B=9,54 ; p<0,01)$ apresentaram significância. Isso significa que a relação do lucro, a relação com o benefício utilitário é inversamente proporcional, ou seja, quanto menor o benefício utilitário, maior a influência no aumento do lucro do posto em relação ao próprio posto. Também é possível perceber que o aumento do preço influencia o aumento do lucro.

$\mathrm{Na}$ situação em que o preço do estabelecimento está menor que a média de mercado e com os concorrentes > 3, a variância explicada é de $45,4 \%$, apenas o preço apresentou significância $(B=11,09 ; p<0,01)$. Isso significa que nesses casos, o aumento do preço influencia o aumento do lucro proveniente da venda de combustível do posto em relação ao próprio posto.

$\mathrm{Na}$ situação em que o preço do estabelecimento está maior que a média de mercado e com os concorrentes $\leq 3$, a variância explicada é de $0,1 \%$, apenas 0 benefício utilitário apresentou significância $(B=0,02 ; p<0,04)$. Isso significa que nesses casos, quanto maior o benefício utilitário, maior a influência no aumento do lucro proveniente da venda de combustível do posto em relação ao próprio posto.

$\mathrm{Na}$ situação em que o preço do estabelecimento está maior que a média de mercado e com os concorrentes > 3, a variância explicada é de 4,2\%, apenas o preço não apresentou significância, o benefício informativo $(B=-0,1 ; p<0,01)$ e 0 benefício utilitário $(B=-0,08 ; p<0,01)$. Nesse caso, os resultados mostraram que em relação ao benefício informativo, quanto menor ele for, maior será a influência no aumento do preço e o mesmo pode ser observado com o benefício utilitário. 
Tabela 9: Análise da variável dependente lucro em relação ao próprio posto.

\begin{tabular}{|c|c|c|c|c|c|c|c|}
\hline Situação & Concorrência & $\begin{array}{c}\mathrm{R}^{2} \\
\text { ajustado }\end{array}$ & $\begin{array}{c}\text { Variável } \\
\text { independente }\end{array}$ & B & $\begin{array}{c}\text { Erro } \\
\text { Padrão }\end{array}$ & $\beta$ & $\mathrm{P}$ \\
\hline \multirow{8}{*}{$\begin{array}{c}\text { Preço do } \\
\text { estabelecimento } \\
\text { menor que a } \\
\text { média de } \\
\text { mercado }\end{array}$} & \multirow{4}{*}{$\begin{array}{c}\leq 3 \\
\text { concorrentes }\end{array}$} & \multirow{4}{*}{.431} & Constante & .16 & .02 & & .00 \\
\hline & & & $\begin{array}{l}\text { Benefício } \\
\text { informativo }\end{array}$ & -.02 & .01 & -.02 & .07 \\
\hline & & & $\begin{array}{c}\text { Benefício } \\
\text { utilitário }\end{array}$ & -.03 & .01 & -.03 & .01 \\
\hline & & & $\begin{array}{l}\log \text { preço } \\
\text { relativo } \\
\text { médio total } \\
\text { por posto }\end{array}$ & 9.54 & .18 & .66 & .00 \\
\hline & \multirow{4}{*}{$\begin{array}{c}>3 \\
\text { concorrentes }\end{array}$} & \multirow{4}{*}{.459} & Constante & .06 & .03 & & .03 \\
\hline & & & $\begin{array}{l}\text { Benefício } \\
\text { informativo }\end{array}$ & .01 & .02 & .01 & .81 \\
\hline & & & $\begin{array}{l}\text { Benefício } \\
\text { utilitário }\end{array}$ & .04 & .02 & .04 & .12 \\
\hline & & & $\begin{array}{l}\text { log preço } \\
\text { relativo } \\
\text { médio total } \\
\text { por posto }\end{array}$ & 11.09 & .29 & .67 & .00 \\
\hline \multirow{8}{*}{$\begin{array}{c}\text { Preço do } \\
\text { estabelecimento } \\
\text { maior que a } \\
\text { média de } \\
\text { mercado }\end{array}$} & \multirow{4}{*}{$\begin{array}{c}\leq 3 \\
\text { concorrentes }\end{array}$} & \multirow{4}{*}{.001} & Constante & .01 & .02 & & .59 \\
\hline & & & $\begin{array}{l}\text { Benefício } \\
\text { informativo }\end{array}$ & -.01 & .01 & -.01 & .47 \\
\hline & & & $\begin{array}{c}\text { Benefício } \\
\text { utilitário }\end{array}$ & .02 & .01 & .03 & .03 \\
\hline & & & $\begin{array}{l}\log \text { preço } \\
\text { relativo } \\
\text { médio total } \\
\text { por posto }\end{array}$ & -.37 & .24 & -.02 & .12 \\
\hline & \multirow{4}{*}{$\begin{array}{c}>3 \\
\text { concorrentes }\end{array}$} & \multirow{4}{*}{.042} & Constante & .26 & .03 & & .00 \\
\hline & & & $\begin{array}{l}\text { Benefício } \\
\text { informativo }\end{array}$ & -.10 & .02 & -.13 & .00 \\
\hline & & & $\begin{array}{c}\text { Benefício } \\
\text { utilitário }\end{array}$ & -.08 & .02 & -.10 & .00 \\
\hline & & & $\begin{array}{l}\log \text { preço } \\
\text { relativo } \\
\text { médio total } \\
\text { por posto }\end{array}$ & -.65 & .45 & -.03 & .15 \\
\hline
\end{tabular}

Nesse estudo foram observados: a influência do preço, benefício informativo e utilitário no lucro proveniente da venda de combustíveis dos postos em relação ao 
próprio posto. $O$ benefício informativo mostrou-se significativo no caso em que 0 posto está com o preço acima da média de mercado e possui mais de três concorrentes. Nesse caso, quanto menor o benefício informativo, maior a sua influência no lucro proveniente da venda de combustível. Os resultados também mostram que o benefício utilitário apresenta significância quando o posto possui até três concorrentes e esta com o preço abaixo do preço de mercado. Nesse caso, quanto menor o benefício utilitário maior o lucro. Nos casos em que o preço está acima do preço de mercado e com até três concorrentes, quanto maior o benefício utilitário, maior o lucro, contudo, quando existem mais de três concorrentes, a relação se inverte, ou seja, quanto menor o benefício utilitário, maior a influência no lucro. Já o preço apresentou significância apenas quando o preço está abaixo do preço de mercado, independente do número de concorrentes a relação é positiva, variando apenas o coeficiente. Nesses casos, quanto maior o preço, maior a influência no lucro proveniente da venda de combustíveis em relação ao próprio posto. Koderish, Wuebker, Baumgarten e Baillie (2007) afirmam em seu estudo que, os bancos tentam agregar diversos produtos para serem vendidos junto com um desconto especial a fim de aumentar a lucratividade. No estudo aqui apresentado não foi possível observar produtos agregados. Todavia, ao se observar postos que aumentam a quantidade de serviços ofertados para o cliente e aumento da lucratividade, só foi significante em um caso: de revendedores com até três concorrentes e com o preço abaixo do preço de mercado.

Já no estudo de Oliveira-Castro, Foxall, James, Pohl, Dias e Chang (2008) no qual eles fizeram uma pesquisa para descobrir o brand equity baseado nas percepções do consumidor que esta relacionado aos benefícios utilitários e informativos dos produtos, este de acordo com eles pode ser utilizado para medir a performance da empresa, no estudo deles eles citam apenas market share e receita como medidas de performance, para ambas o preço não é muito influente. No estudo aqui apresentado, utilizou-se lucro como uma medida de performance e para este o preço foi o mais influente, ao contrário do que aconteceu nos outros indicadores de performace utilizado no estudo de Oliveira-Castro, Foxall, James, Pohl, Dias e Chang (2008). 


\section{CONCLUSÕES E RECOMENDAÇÕES}

O objetivo geral: Investigar a influência do benefício utilitário, benefício informativo e preço sobre a quantidade de clientes, receita e lucro oriundo da venda de combustíveis automotivos foi atingido. Assim como os objetivos específicos: Analisar a relação preditiva do preço, benefício utilitário e informativo sobre indicadores de performance no mercado relacionada a quantidade de clientes, receita e lucro proveniente da venda de combustíveis; analisar a relação preditiva do preço, benefício utilitário e informativo sobre indicadores de desempenho do próprio estabelecimento relacionada a quantidade de clientes, receita oriunda da venda de combustíveis e lucro proveniente da venda de combustíveis.

A partir desse trabalho conclui-se que como um todo, as regressões ( $R^{2}$ ajustado) foram melhores para as 3 primeiras do que para as 3 últimas. Isso quer dizer que benefício utilitário, benefício informativo e preço influenciam mais na alteração das taxas de quantidade de cliente, receita e lucro dos postos em relação a outros postos e não muito para alterar as taxas de quantidade de cliente, receita e lucro dos postos em relação a eles mesmos. Ou seja, a compreensão dessas variáveis melhoram a competitividade do posto no mercado, mas não é muito eficaz para superar seu próprio desempenho, com exceção do lucro que no caso em que o preço está abaixo da média de mercado, possui um $\mathrm{R}^{2}$ ajustado alto.

Gerencialmente o trabalho foi efetivo para que os gestores saibam priorizar as estratégias que tornam o estabelecimento mais competitivo no mercado de revendedores de combustíveis. E cientificamente contribuiu para a compreensão do processo de escolha do consumidor.

O estudo apresentado teve como limitações o fato de não ser uma amostra aleatória, já que a amostra foi uma determinada rede de revendedores de combustíveis automotivos. Para aumentar o $\mathrm{R}^{2}$ ajustado, poder-se-ia também utilizar mais variáveis dependentes, uma das sugestões para um próximo trabalho é utilizar o tempo como variável independente. Além disso, poder-se-ia elaborar um questionário para os clientes a fim de se aprofundar o conceito de benefício informativo. 


\section{REFERÊNCIAS}

Agência Nacional do Petróleo, Gás Natural e Bicombustíveis - ANP. Disponível em <http://www.anp.gov.br/postos/consulta.asp>. Acesso em 30 de março de 2010.

ANDERSON, E. E.. The Measurement of Buyer Brand Preference and Indifference under Changing Terms of Trade. American Journal of Agricultural Economics, Vol. 56, No. 1 (Feb., 1974), pp. 122-128

ANDRADE, V. M. Gerenciamento de impressões em serviços de hospitalidade: investigando o servicescape em hotéis com base na metáfora teatral. In: ENCONTRO NACIONAL DA ASSOCIAÇÃO NACIONAL DOS PROGRAMASDE PÓS-GRADUAÇÃO E PESQUISA EM ADMINISTRAÇÃO,28., 2004, Curitiba. Anais. Curitiba: EnAnpad, 2004.

BOYD, E. A.. Dramatic changes in distribution will require renewed focus on pricing and revenue management models. Journal of Revenue \& Pricing Management, Apr 2004, Vol. 3 Issue 1, p100-103, 4p.

Boletim da Qualidade dos Combustíveis Automotivos - PMQC. Disponível em <http://www.anp.gov.br/?pg=28945>. Acesso em 11 de junho de 2010.

BOULDING, W.; KALRA, A.; STAELIN, R.; ZEITHAML; V. A.. A Dynamic Process Model of Service Quality: From Expectations to Behavioral Intentions. In: Journal of Marketing Research, Vol. 30, No. 1 (Feb., 1993), pp. 7-27

CAPUTO, E. S.; MACEDO, M. A. S.; NOGUEIRA, H. G. P.. Avaliação de marcas: uma aplicação ao caso BOMBRIL. In: RAE-eletrônica, v. 7, n. 2, Art. 21, jul./dez. 2008.

COZBY, P. C.. Métodos e Pesquisa em Ciências do Comportamento. São Paulo: Atlas, 2009.

DAY, G. S. e WENSLEY R.. Assessing Advantage: A Framework for Diagnosing Competitive Superiority. Journal of Marketing, Vol. 52, April 1988, pp 1-20. 
DUDLEY, M.. Competition by Choice: The Effect of Consumer Search on Firm Location Decisions. The American Economic Review, Vol. 80, No. 5 (Dec., 1990), pp. 1092-1104.

EHRENBERG, A. S. C.; UNCLES, M. D.; GOODHARDT, G. J.. Understanding brand performance measures: using Dirichlet benchmarks. Journal of Business Research (2004) 1307-1325

Fecombustíveis. Disponível em: <http://www.fecombustiveis.org.br/tributacao.html> Acesso em 10 de junho de 2010

FERRELL, O.C.; HARTLINE, M. D.; LUCAS, G. H.. Marketing Strategy. Canada: 2002.

FISCHMANN, A.A. e ZILBER, M.A. Utilização de indicadores de desempenho como instrumento de suporte à gestão estratégica. In: Encontro Anual da Associação Nacional dos Programas de Pós-Graduação em Administração, XXIII, Foz do Iguaçu 1999.

FOXALL, G. R. (1997) Marketing Psychology: the paradigm in the wings. 1. ed. London: Macmillan Press LTD

FOXALL, G. R.; OLIVEIRA-CASTRO, J. M.; JAMES, V.K. e SCHREZENMAIER, T. C. (2006). Consumer behavior analysis: the case of brand choice. rPOT, v. 6, janjun, 2006, p. $50-79$.

GREWAL, D.; KRISHNAN, T; BAKER, J. e BORIN, N. The Effect of Store Name, Brand Name and Price Discounts on Consumers' Evaluations and Purchase Intentions. In: Journal of Retailing, Volume 74 (Fall, 1988): 331-352.

HAUSER, J. R. e SHUGAN, S. M.. Defensive Marketing Strategies. Marketing Science, Vol. 2, No 4, 1983, pp 319-360.

ICÓ, J. A.; BRAGA, R. P.. EBITDA: lucro ajustado para fins de avaliação de desempenho operacional. Revista Contabilidade e Informação Conhecimento e Aprendizagem, Unijuí, ano 3, n. 8, jan./mar. 2001., p. 39-47. 
KENG, K. A. e EHRENBERG, A. S. C.. Patterns of Store Choice. Journal of Marketing Research, Vol. 21, No. 4 (Nov., 1984), pp. 399-409

KODERISH, M.; WUEBKER, G.; BAUMGARTEN, J. e BAILLIE, J.. Bundling in banking - A powerful strategy to increase profits. Journal of Financial Service Marketing. Vol 11, No 3, 2007, pp 268-276.

LARANJEIRAS, S.. A Reestruturação das Telecomunicações e os Sindicatos. Revista Brasileira de Ciências Sociais,vol.18, 2003, ํ52.

LEVITT, T.. The Globalization of Markets. Harvard Business Review, 61 (1983), 92-102.

LIMA, A. L. S.. Identificação dos valores do consumidor na decisão de compra em situação de baixo envolvimento. Rio de Janeiro: Universidade Estácio de Sá, 2008. Tese (Mestrado) - Curso de Mestrado em Administração e Desenvolvimento Empresarial - MADE, Universidade Estácio de Sá, 2008.

MIRANDA, L. C.; WANDERLEY, C. A.; MEIRA, J. M.. Garimpando na imprensa especializada: uma metodologia alternativa para coleta de indicadores de desempenho gerencial. Anais do VI Congresso Internacional de Custos, Portugal, 1999.

MIRANDA, L. C.; WANDERLEY, C. A.; MEIRA, J. M..; SILVA, A. C. M.. Indicadores de desempenho empresarial divulgados por empresas norte-americanas. Anais do 2o Seminário USP de Contabilidade, São Paulo, 2002.

NETHERLANDS, S.. Should we delight the customer? In: Journal of the Academy of Marketing Science, p. 86-94, Volume 28, Number 1 / December, 2000.

NEVES, J. A. D. e COSTA, A. M.. Fatores de Localizaçăo de Postos de Combustíveis em Fortaleza. RAC, Curitiba, Edição Especial 2008, p. 175-192

OLIVEIRA-CASTRO, J. M.; FOXALL, G. R.; SCHREZENMAIER, T. C.. Patterns of Consumer Response to Retail Price Differentials. The Service Industries Journal, Vol.25, No.3, April 2005, pp.309-335. 
OLIVEIRA-CASTRO, J. M.; FOXALL; JAMES V.K.; POHL R. H.B. F.; DIAS M.B.; CHANG S.W.. Consumer-based brand equity and brand performance. The Service Industries Journal, Vol. 28, No. 4, May 2008, 445-461

PARENTE, J. G.; KATO, H. T.. Área de Influência: Um Estudo no Varejo de Supermercados. Revista de Administração de Empresas (FGV), São Paulo, v. 41, n. Abr./Jun, p. 46-53, 2001.

PASA, M.; SHUGAN, S. M.. The Value of Marketing Expertise. Management Science, Vol. 42, No 3, March 1996, pp 370-388.

PETERS FILHO, T. A.. Mensuração da influência de qualidade, valor, satisfação e envolvimento do consumidor sobre intenções comportamentais em restaurantes finos da cidade de São Paulo. São Paulo: EAESP/FGV, 2003. (Tese de Doutorado apresentada ao Curso de Pós-Graduação da EAESP/FGV, Área de Concentração: Mercadologia).

PINTO M.; SILVA,E. O brilho da bandeira branca: Concorrência no mercado de combustíveis do Brasil. Anais XXXII Encontro Nacional de Economia, João Pessoa, 2004.

POHL, R. H. B. F.. Efeitos do nível de reforço informativo das marcas sobre a duração do comportamento de procura. Brasília: Universidade de Brasília, 2004. Tese mestrado psicologia.

PORTO, R. B.. Correspondência dizer-fazer em escolha de marcas: Influência das estratégias de Marketing no ponto-de-venda e das experiências anteriores dos consumidores. Tese de doutorado apresentado ao Instituto de Psicologia da Universidade de Brasília, como requisito à obtenção do título de Doutor em Ciências do Comportamento.

PRUSHAM, V. H., Marketing: 101 segredos do Marketing para conquistar e manter clientes.São Paulo: Futura, 1999.

RATHMELL, J. M.. What Is Meant by Services?. In: The Journal of Marketing, Vol. 30, No. 4 (Oct., 1966), pp. 32-36 
SAMARA, B. S.; MORSCH, M. A.. Comportamento do consumidor: conceitos e casos. São Paulo: Pearson Prentice Hall, 2005.

SEMENIK, R. e BAMOSSY G. J.. Princípios de Marketing: uma perspectiva global. São Paulo, 1995.

Mendes F.; Melo F.; Palmeiras R.; Lopes R.. Top of mind. Jornal de Brasília 2009. Brasília, 2009, 111p., il.

VINOD, B.. The complexities and challenges of the airline fare management process and alignment with revenue management. Journal of Revenue \& Pricing Management, Jan 2010, Vol. 9 Issue 1/2, p137-151

WALTERS, R. G.. Assessing the Impact of Retail Price Promotions. Journal of Marketing, Vol 55, April 1991, pp. 17-28.

WRIGHT, P.. Consumer Choice Strategies: Simplifying vs. Optimizing. Journal of Marketing Research, Vol. 12, No. 1 (Feb., 1975), pp. 60-67 